\title{
Frequency-dependent site factors for the Icelandic strong- motion array from a Bayesian hierarchical model of the spatial distribution of spectral accelerations
}

\author{
Sahar Rahpeyma a), Benedikt Halldorsson ${ }^{\text {,cc) }}$, Birgir Hrafnkelsson ${ }^{\mathrm{d})}$, and Sigurjón Jónsson ${ }^{\mathrm{e})}$
}

\begin{abstract}
The earthquake ground motions of over 1700 earthquakes recorded on a small aperture strongmotion array in south Iceland (ICEARRAY I) that is situated on a relatively uniform site condition characterized as rock, exhibit a statistically significant spatial variation of ground motion amplitudes across the array. Both earthquake and microseismic horizontal-to-vertical spectral ratios (HVSR) have been shown to exhibit distinct and in some cases bimodal peaks in amplification, indicating site resonance at periods of 0.1-0.3 $\mathrm{s}$, a phenomenon that has been attributed to a surface layer of lava-rock lying above a sedimentary layer, a structure that is then repeated with depth under the array. In this study, we implement a Bayesian hierarchical model (BHM) of the seismic ground motions that partitions the model residuals into earthquake event term, station term, and event-station term. We analyzed and compared peak ground acceleration (PGA) with the $5 \%$ damped pseudo-acceleration response spectrum (PSA) at oscillator periods of $\mathrm{T}=0.05-1.0 \mathrm{~s}$. The results show that the event terms, dominate the total variability of the ground motion amplitudes over the array. However, the station terms are shown to increase in the period range of 0.1-0.3 s on most stations and to different extents, leading to an increase in the overall variability of ground motions at those periods, captured by a larger inter-station standard deviation. As the station terms are a measure of how much the ground motions at those stations deviate from the array average, they act as proxies for localized site effects and amplification factors. These results, improve our understanding of the key factors that affect the variation of seismic ground motions across the relatively small area of ICEARRAY I. This approach can help to improve the accuracy of earthquake hazard assessments on local scales, which in turn could contribute to more refined seismic risk assessments and engineering decision making.
\end{abstract}

\section{Keywords}

Bayesian hierarchical model, earthquake, array, site effects, variabilities, ground motion model.

\footnotetext{
a) Faculty of Civil and Environmental Engineering, School of Engineering and Natural Sciences, University of Iceland, Reykjavík, Iceland

b) Earthquake Engineering Research Centre \& Faculty of Civil and Environmental Engineering, School of Engineering and Natural Sciences, University of Iceland, Selfoss, Iceland

c) Geoscience Research Group, Division of Processing and Research, Icelandic Meteorological Office, Reykjavík, Iceland

d) Department of Mathematics, Faculty of Physical Sciences, School of Engineering and Natural Sciences, University of Iceland, Reykjavik, Iceland

e) King Abdullah University of Science and Technology (KAUST), Physical Science and Engineering Division (PSE),

Thuwal, 23955-6900, Saudi Arabia
}

Corresponding author:

Sahar Rahpeyma, Faculty of Civil and Environmental Engineering, School of Engineering and Natural Sciences, University of Iceland, Reykjavík, Iceland.

Email: $\underline{\text { sahar@hi.is }}$ 


\section{Introduction}

For a reliable probabilistic seismic hazard assessment (PSHA), a decent prediction of mean values along with uncertainties of a ground motion model (GMM) needs to be applied. There are two components of uncertainty, both of which are important. Epistemic uncertainty, associated with the lack of knowledge and measurements as to the correct median ground motions and aleatory variability, expressing random variability in observed ground motions about the median prediction curve. Primarily, aleatory variability arises from different sources such as earthquake rupture, seismic wave propagation path, and local site effects and has generally been captured by the standard deviation of the GMM (Abrahamson and Youngs, 1992; Al Atik et al., 2010; Bommer and Crowley, 2006; Boore et al., 1997). It has been extensively investigated that the level of aleatory variability is a key parameter that influences seismic hazard calculations (Atkinson, 2006; Strasser et al., 2009; Zhao et al., 2006). The total variability of GMMs differs from event-to-event and changes from site-to-site (Abrahamson and Youngs, 1992; Brillinger and Preisler, 1984, 1985; Joyner and Boore, 1993). One of the important lessons that has emerged from catastrophic earthquakes is that local site characterization has a profound impact on the level of ground motion intensities and consequently the damage distribution (e.g., Mexico City earthquake, 1985; Loma Prieta earthquake, 1989; Kobe earthquake, 1995; İzmit earthquake, 1999; and Chi-Chi earthquake, 1999). This is mainly because of the varying subsoil properties such as impedance contrasts or thicknesses of sedimentary layers over short distances in which subsoil layers act as different filters to incoming seismic waves and amplify/de-amplify ground motions at certain frequencies or change the fundamental frequency, respectively. Inappropriate modeling of site effects can thus introduce large variability into attenuation models that contributes to an inaccurate PSHA.

Estimation of systematic ground motion variations due to local site conditions is of great engineering interest with important implications for earthquake resistant design, seismic hazard assessment, and urban planning, where the main purpose is to reduce human and economic losses that future ground motions may cause (Kramer, 1996). In the current version of seismic code provisions (e.g., Eurocode 8) site effects are taken into account through the suggestion of appropriate elastic design spectra and amplification factors based on different site categories. Derras et al. (2017) investigated the capability of various sitecondition proxies and showed that although the choice of different site-condition proxies has no impact on the median ground motion prediction, it does impact the level of aleatory variability. $V_{S 30}$, i.e., the average shear-wave velocity for the upper $30 \mathrm{~m}$ of the subsoil profile (Borcherdt and Glassmoyer, 1992) was found to be the best single proxy at short periods, while $f_{0}$, i.e., the fundamental frequency of the subsoil and $H_{800}$, i.e., the depth beyond which $V_{S}$ exceeds $800 \mathrm{~m} / \mathrm{s}$ perform better at longer periods. Furthermore, the results of this study indicate that considering pairs of site-condition proxies can significantly improve the prediction (i.e., reduction in the aleatory variability). In Eurocode $8, V_{\mathrm{S} 30}$ is used along with other mechanical soil properties to define different soil types (European Committee for Standardization, 2004).

In Iceland, the site conditions at strong-motion stations have been classified as "rock" and "stiff soil", respectively and qualitatively associated with relatively high values of 
average shear wave speed in the uppermost 30 meters. Therefore, both site conditions are believed to be associated with a relatively low amplitude amplification that is expected to be uniform (over frequency) (Sigbjörnsson et al., 2014). However, it has not been conclusively shown, and sparsity of data on "stiff soil" presumably would preclude any reliable results for that class. Finally, different site-condition proxies have not been examined for Icelandic site conditions. Recent studies have, however, highlighted the unique and significant site effects that may be observed on top of a geological soil structure that is characterized by Holocene lava layers on top of sedimentary layers - a sequence that may be repeated with depth until the bedrock is reached. Moreover, such site effects are reported to have notable variations even over relatively short distances, which emphasizes the importance of carrying out localized studies on site effects. In 2002, Bessason and Kaynia (2002) showed considerable site amplification differences at the east and west abutments of the 80-meter long Thjorsa Bridge in South Iceland, due to different subsoil structures. Later, we described frequency-dependent site effects, manifested through horizontal-to-vertical spectral ratios (HVSR) of ground motions, across the town of Hveragerði, South Iceland, where the first Icelandic strong-motion array (ICEARRAY I) is located (Rahpeyma et al., 2016). The findings of this study indicate that even though the amplification levels may remain relatively low, the fundamental resonance frequency of the site is in accordance with what is known about the geological structure and varies systematically between stations. In particular, significant differences between site amplification of the lava-rock structure vs. the old bedrock that underlies portions of the array were observed.

In engineering applications, the principal tools for estimating ground motion are the GMMs, which provide the conditional distribution of the ground motion parameter of interest that depends on parameters describing the source, path, and site effects. The ground motion parameters of interest are commonly peak ground acceleration (PGA) as well as pseudo-acceleration response spectrum (PSA) at different periods. For a selected ground motion parameter and a set of independent seismic parameters (e.g., moment magnitude, source-to-site distance, focal depth, etc.), empirical GMMs are classically developed using Linear/Nonlinear regression analysis and fitting a functional form to observations using either the one-stage mixed-effect regression algorithm proposed by Abrahamson and Youngs (1992) or two-stage algorithm of Joyner and Boore (1993). Regression analysis is performed to obtain the best fit, which is essentially a combination of predictor variables constituting a median prediction (usually at a logarithmic scale), that minimizes the residual variability.

Contrary to the spatially correlated intra-event errors due to the common source and wave propagation paths, and similar site conditions, the spatial correlation between intraevent residuals has been mainly ignored in developing GMMs. However, during recent decades, the importance of assessing seismic risk for spatially distributed lifeline networks and infrastructures has motivated researchers to take into account spatial correlation in developing GMMs (Hong et al., 2009; Jayaram and Baker, 2009). Jayaram and Baker (2010) proposed a multistage algorithm to account for the spatial correlation by adopting the idea of the classical geostatistical analysis (Zimmerman and Stein, 2010). More recently, Ming et al. (2019) introduced a one-stage ground-motion estimation algorithm to 
fit GMMs with spatial correlation. Both of the abovementioned methods were proposed under the maximum likelihood estimation (MLE) framework.

Recently, we proposed a practical Bayesian inference scheme in order to estimate the contribution of source, path, and site effects given the spatial distribution of PGA recorded on a dense small-aperture strong-motion array (ICEARRAY I) that is located within an urban area in the town of Hveragerði in south Iceland (Rahpeyma et al., 2018). The proposed model is a Bayesian Hierarchical Model (BHM) tailored for spatial strong motion data that offers a flexible probabilistic framework for multilevel modeling of earthquake ground motion parameters, in which a collection of random variables can be decomposed into a series of conditional models. Since the BHM represents the model parameters in terms of the posterior probability densities, the BHM model successfully describes the relative contribution of source, path, and site effects to the overall GMM uncertainty, through its event, event-site, and site-terms, respectively, along with their associated uncertainties. It is worth mentioning that contrary to the MLE methods in applying spatial correlation in developing GMMs (e.g., Jayaram and Baker, 2010; Ming et al., 2019) the multilevel Bayesian approach implements prior distribution along with the likelihood function instead of maximizing the likelihood function alone. Furthermore, in the BHM framework station-terms and event-station terms are defined spatially correlated using separated covariance function from the Mátern family.

Later, we implemented the BHM to estimate and compare site effects on two Icelandic strong-motion arrays with different geological settings, one in south Iceland (ICEARRAY I) and the other in north Iceland (ICEARRAY II) (Rahpeyma et al., 2018). The results highlight that although the site conditions across ICEARRAY I have been classified as uniform (i.e., "rock", and with a relatively flat topography) station terms contribute to $\sim 13 \%$ of the total variability in the amplitudes of predicted ground motions across the array. The contribution of site effect variability across ICEARRAY II was found to be significantly larger or up to $\sim 57 \%$, consistent with the observation that it is built on top of much more variable subsoil structure and topography. The specific standard deviations give us the chance to quantitatively find out to what extent the respective earthquake source, path, and site effects contribute to the overall variability of ground motion across the region. As a matter of fact, removal of the repeatable components such as station or path terms from the intra-event residuals reduces the scatter of event- and-station residuals and makes it possible to estimate single-station sigma, which results in more accurate PSHA calculations by avoiding double-counting of some parts of the variability (Atkinson, 2006).

Here, we extend the BHM model for PGA to PSA over the period range that is of most common engineering interest (broadly defined as $T=0.05-1.0 \mathrm{~s}$ ). In general, a BHM is constructed hierarchically on multiple levels. In this study, we construct a three-level BHM: data level, latent level, and hyperparameter level. The data level describes the distributional model for the observation conditioned on the model parameters. These parameters are classified as latent parameters and hyperparameters. The earthquake PGA and PSA values recorded by ICEARRAY I strong-motion stations constitute the data level. The latent level describes the prior probability distribution of the latent parameters, some of which are found in the distributional model of the observations. Examples of latent parameters are e.g., the coefficients of the GMM and the event and station residual terms, etc. The purpose of these 
prior distributions is to regularize or constrain the latent parameters in a sensible way to improve their inference. The prior distributions of latent parameters depend on hyperparameters, in this case the standard deviation of the distribution describing the corresponding latent parameter. The hyperparameter level thus consists of the prior distributions of the hyperparameters at the data and latent levels.

\section{The ICEARRAY I strong-motion}

In 2007, the first small-aperture Icelandic strong-motion array (ICEARRAY I, Figure 1) was deployed in the town of Hveragerði in South Iceland with the aim of monitoring and recording strong events in the region, quantifying spatial variability of strong-motion over short distances, and enabling earthquake source processes research (Halldorsson et al. 2009). The array covers around $1.23 \mathrm{~km}^{2}$ and consists of 13 accelerometric stations with inter-station distances ranging from 50-1900 m. According to the geological information and borehole data, most of Hveragerði is located on a young ( 5000 years old) and competent lava-rock layer, which in turn is underlain by a layer of softer sedimentary deposits (Rahpeyma et al. 2016). This structure is then essentially repeated below because another lava-rock layer ( 10,000 years old) lies underneath, one that flowed in early Holocene i.e., shortly after the glacial retreat and the resulting isostatic ascendance of the seabed. This type of subsoil structure thus introduces a reversal in shear wave velocity with depth. While no information about the thickness of the lower layer exists, it flowed from the same volcanic fissure during early Holocene and based on the spatial extent of the lava it is likely of similar thickness as the uppermost lava layer (Sæmundsson and Kristinsson, 2005). Such geologic profile is a typical layering encountered primarily in geologically younger parts of Iceland in the vicinity of the volcanic zones, where during Holocene basaltic lavas flowed intermittently and very localized.

The deployment of ICEARRAY I in the south Iceland seismic zone (SISZ) ushered in a new era of earthquake strong-motion studies in Iceland, and since then the size of the Icelandic strong-motion data set has dramatically increased. On 29 May 2008 at 15:45 local time, the $M_{\mathrm{w}} 6.3$ Ölfus earthquake occurred in the western part of the SISZ. The ICEARRAY I network recorded the main-shock and more than 1700 of its aftershocks of $M_{1}$ 0.42-4.75 at hypocentral distances of $\sim 1.8-17.8 \mathrm{~km}$ over the course of several months. As indicated in Figure 1, the first motion originated approximately $6.5 \mathrm{~km}$ east-southeast of the town and the spatial distribution of aftershocks outlined a pair of parallel, nearvertical north-south striking right-lateral strike-slip faults that are approximately $4.5 \mathrm{~km}$ apart. Although the mainshock epicenter was located on the eastern fault, most of the aftershocks occurred on the western fault that ruptured approximately 2 seconds after the first and lies only 1-2 km from Hveragerði (Halldorsson et al., 2010; Halldorsson and Sigbjörnsson, 2009). Contrary to the assigned uniform "rock" site condition across ICEARRAY I, consistent and significant ground motion variations were observed at the strong-motion stations (Rahpeyma et al., 2016).

In our earlier work, we studied the site effects across ICEARRAY I from horizontal-tovertical-spectral-ratios (HVSR) and Standard Spectral Ratios (SSR), which showed two separate and predominant frequencies at some of the strong-motion stations situated on top 


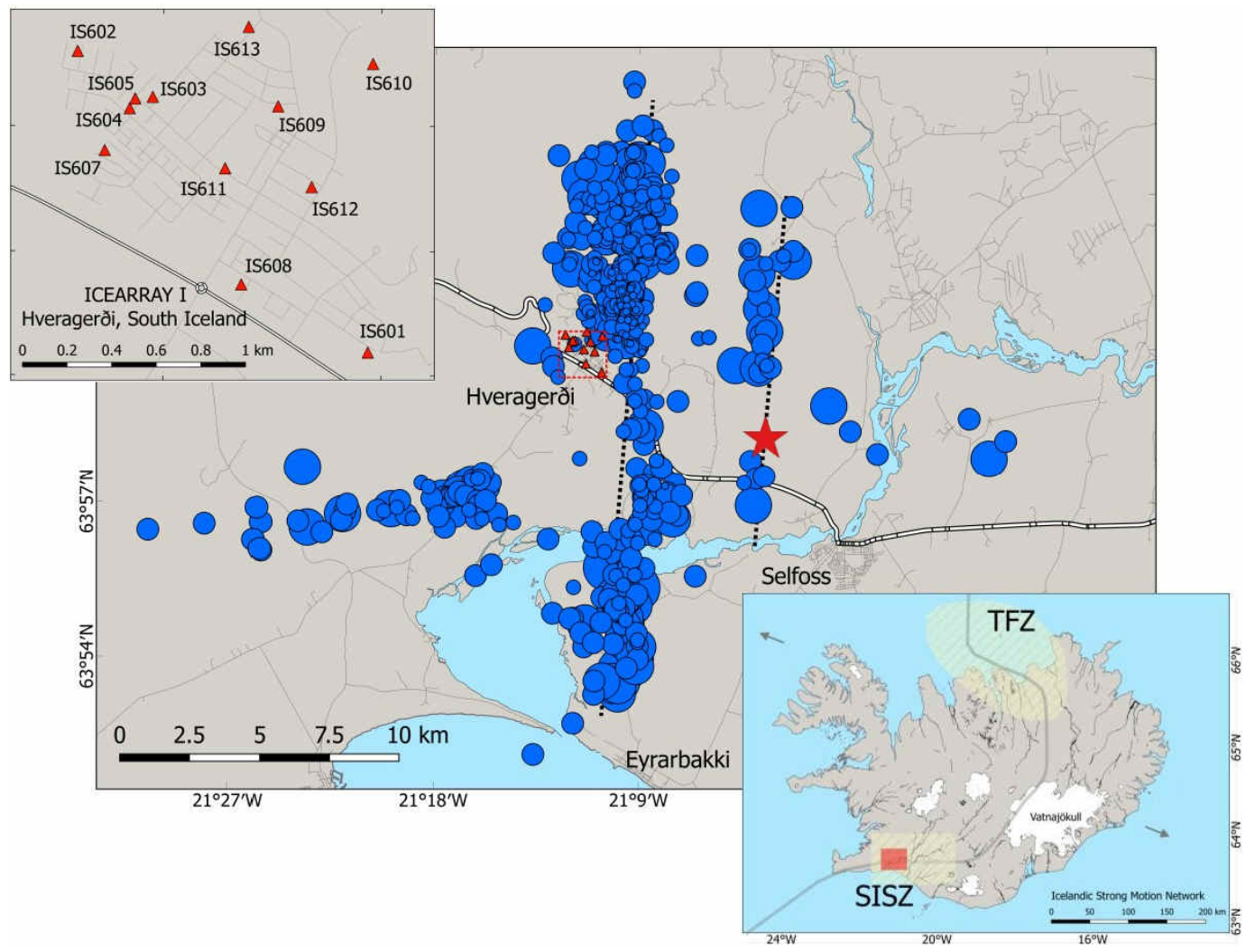

Figure 1. Locations of one month of aftershocks (blue circles) following the 15:45 UTC 29 May 2008 magnitude 6.3 earthquake (red star marks the epicenter) in the South Iceland Seismic Zone (SISZ), which ruptured two parallel faults (approximated by the black dashed lines).

The bottom right inset shows the present-day rift axis of the Mid-Atlantic Ridge (gray line) in Iceland, with the Tjörnes Fracture Zone (TFZ) in the north and the SISZ indicated by the yellow shaded areas; the red rectangle marks the area shown in the main figure. The top left inset shows the locations of the ICEARRAY strong-motion stations (triangles) in the town of Hveragerði.

of the lava rock (Rahpeyma et al., 2016, 2017). These profiles were found to act as a transfer function that amplifies the surface ground motions at certain predominant frequencies of resonance, with the extent of the amplification depending on the frequency content of the incident seismic motion. The site effects in Hveragerði are thus expected to be a manifestation of the effects of at least two velocity reversals on seismic wave amplification. The HVSR amplification curves for all earthquake recordings at the selected ICEARRAY I strong-motion stations in this study are presented in Figure 2 over the frequency range of $0.5-20 \mathrm{~Hz}$, along with the geometric mean HVSR and the associated $\pm 1 \sigma$ (Rahpeyma et al., 2016). Despite the small aperture of ICEARRAY I, there are noticeable differences in the HVSR results across the array. Some stations exhibit bimodal amplification curves with peaks at $3-4 \mathrm{~Hz}(0.25-0.33 \mathrm{~s})$ and at $8-9 \mathrm{~Hz}(0.11-0.13 \mathrm{~s})$ with one mode being more dominant and of relatively larger amplitude than the other (see e.g., HVSR at IS605, IS604, IS608) while other stations have a single narrow-band peak of relatively low amplitudes (e.g., IS602) or amplification curves of relatively high amplification over a wide frequency range (e.g., IS601, IS603), or even very low and uniform amplification curves across the frequency range (IS609). We note that while the HVSR results appear to diverge at around $10 \mathrm{~Hz}$ for stations IS611 and IS612 the amplifications are low (near unity) and those discrepancies are associated with the apparent "signature" peak of the station IS609 HVSR 


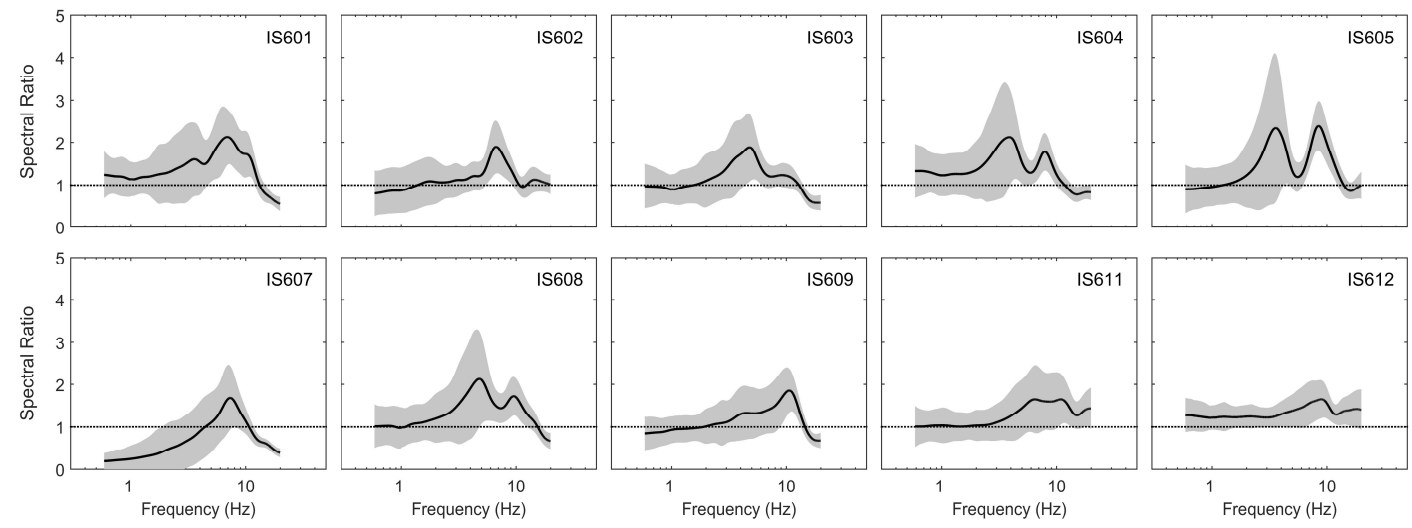

Figure 2. Mean HVSR $\pm 1 \sigma$ from earthquake data for the ten ICEARRAY I strong motion stations located on lava-rock in Hveragerði, South Iceland.

Black solid and shaded area show mean HVSR and mean HVSR $\pm 1 \sigma$ from earthquake data.

results at that frequency. The signature of IS607 was deemed unreliable due to noise at lower frequencies.

Here we took the same dataset used in Rahpeyma et al. (2019), consists of 610 aftershocks recorded by the ICEARRAY I, and carefully reviewed it to ensure the quality of the recordings. Parametric information for these events is available from the National seismic network (SIL) of the Icelandic Meteorological Office and hypocentral location estimates have been improved using data from a local and temporary seismograph network deployed within two days after the earthquake (Brandsdóttir et al., 2010).

\section{BHM formulation}

In this study, a multi-level BHM is cast in three levels i.e., data level, latent level, and hyperparameter level. At the data level, the conditional density of the observed data is given by a function of model parameters which are defined at the latent and hyperparameter levels. The prior probability distributions for the latent parameters and hyperparameters are given at the latent and hyperparameter levels, respectively. The purpose of these prior distributions is to regularize or constrain the model parameters in a sensible way to improve their inference (for more details see Rahpeyma et al. 2018). The basic model for the prediction of a ground-motion parameter $Y$ dependent on source, path, and site parameters is defined as Equation (1) (Abrahamson and Youngs, 1992; Al Atik et al., 2010):

$$
\begin{gathered}
\log Y_{e s}=\log \mu_{e s}\left(M_{e}, R_{e s}, D_{e}\right)+\delta B_{e}+\delta W_{e s}, \\
e=1, \ldots, N, \quad s=1, \ldots, Q
\end{gathered}
$$

where subscripts $e$ and $s$ represent an event (earthquake) and a station (recording site), respectively. $Y_{e s}$ is the strong-motion parameter of interest for earthquake $e$ recorded at station $s$, and the logarithmic transformation of it is modeled with a Gaussian distribution. The predictive model, $\log \mu_{e s}$, provides the logarithm of the median ground motion in terms of independent seismic variables (e.g., moment magnitude, source-to-site distance and depth of event) for event $e$ at station $s . \delta B_{e}$, the inter-event residuals (i.e., the event term), represent the average shift, corresponding to an individual earthquake, of the observed ground motions from corresponding median estimates of the ground motion model. The 
event terms are assumed to be independent of each other and to follow a Gaussian distribution with zero mean and variance of $\tau^{2} . \delta W_{e s}$, the intra-event residuals within event $e$, on the other hand, represent the difference between an individual observation at station $s$ from the earthquake-specific median prediction (Al Atik et al., 2010; Strasser et al., 2009). The intra-event residuals capture azimuthal variations in source, path, and site effects reflecting the effects of those parameters such as crustal heterogeneity, geological structure, and sub-surface characteristics that are not captured by a distance metric and a siteclassification (Al Atik et al., 2010). Using the BHM model the intra-event residuals can be further classified into three terms:

$$
\delta W_{e s}=\delta S 2 S_{s}+\delta W S_{e s}+\delta R_{e s} .
$$

The station term (i.e., inter-station residual), i.e., $\delta S 2 S_{s}$, represents the average intraevent residual at each station and can be used to scale the ground motion model prediction to a site-specific prediction. The inter-station residual results from the use of simple site parameters, which do not provide a complete site characterization. The station terms are modeled a priori with a mean zero Gaussian distribution with a spatially correlated exponential covariance function (a sub-class of the Mátern family (Cressie and Lahiri, 1993 ) with inter-station variability of $\phi_{S 2 S}^{2}$, smoothness parameter $v_{S 2 S}=0.5$, and range parameter $\Delta_{S 2 S}$ (see Rahpeyma et al., 2018). ${ }^{1} / \Delta_{S 2 S}$ is the decay rate (Stein, 2012) and shows how fast the correlation between observations decreases with distance. It is worth noting that $\delta S 2 S_{S}$ does not include any site-response component such as shear-wave velocity or predominant frequency.

The site- and event-corrected residual, $\delta W S_{e s}$, captures record-to-record variability (the combination of $e$ and $s$ after taking the intra-event and inter-station residuals into account) and can be investigated for other repeatable effects such as variability in incidence angle and systematic wave propagation or path effects. It is the misfit between an individual observation of the amplification at site $s$ due to earthquake $e$ from the average site-specific amplification and is associated with not only path effects but also variability in incidence angle, propagation and other sources of variability across all source-site paths in the dataset. We refer to $\delta W S_{\text {es }}$ as the event-station term and model it as spatially correlated variables from a zero-mean Gaussian field governed by a covariance function from the Mátern family with a marginal variance of $\phi_{S S}^{2}$ and smoothness parameter $v=1.5$, and range parameter $\Delta_{S S}$. Finally, $\delta R_{e s}$ is referred to as the unexplained term and accounts for effects that are not modeled by the other terms. The unexplained terms are modeled as independent terms and are assumed to follow a zero-mean Gaussian distribution with a variance of $\phi_{R}^{2}$.

Consequently, the total variability of the BHM can be separated into two main parts: the inter-event variability and the intra-event variability in which the intra-event variability can further be divided into inter-station variability (i.e., station-to-station variability), event-station variability (i.e., variability between stations within an event), and other unexplained variability (e.g., measurement and model error, etc.). The BHM is found to be a practical tool for many engineering applications, in particular to develop non-ergodic (partially or fully) GMMs and quantify their standard deviation parameters. In particular, the inter-station variability represents the impacts of geological aspects and station conditions separately from the source and path characteristics. Effectively, therefore, the 
total (aleatory) variability of the model in Equation (1) can be quantified with the variance of the sum of the four independent terms presented in Equation (3):

$$
\sigma_{T}^{2}=\tau^{2}+\phi_{S 2 S}^{2}+\phi_{S S}^{2}+\phi_{R}^{2}
$$

The inter-event variance $\left(\tau^{2}\right)$ quantifies the variation between events relative to the average ground motion level predicted by the GMM for each event. The inter-station variance $\left(\phi_{S 2 S}^{2}\right)$ quantifies the variability between stations, which then is primarily a manifestation of the localized variations such as the geological profiles beneath the stations which are not captured by site proxies used in the GMM. It should be noted that in this study from the outset we did not use a proxy for site response in the GMM (see Eq. (4)) due to the generally unknown site effects on the two "rock" types under ICEARRAY I (i.e., old bedrock and lava-rock). Hence, the site terms of our BHM have now effectively revealed the distinct contributions of the localized site condition under each station, which forms a basis for more detailed modeling of the site response. The event-station variance $\left(\phi_{S S}^{2}\right)$ can be defined as a measure of the spatial variability in the ground-motion amplitudes between stations within an event after taking into account the event and station terms. The purpose of this term is to quantify the remaining variations not already captured by the GMM or the event and station terms (e.g., systematic wave propagation effects or path related aspects). Finally, the unexplained term variance $\left(\phi_{R}^{2}\right)$ quantifies the variability in the measurement errors as well as other deviations that are not accounted for by other terms of the model.

Here a simple and commonly used linear predictive function is selected for the logarithm of the median ground motion, $\log \mu_{e s}$. Although GMMs come in a variety of different functional forms, we prefer to use a linear and parsimonious model, in this study, that links ground motion amplitude to the local magnitude of the $e$-th earthquake, $M_{e}$; the hypocentral distance from the $e$-th event to the $s$-th station, $R_{e s}$; and the depth of the origin of the eth earthquake, $D_{e}$, as follows:

$$
\log \mu_{e s}=\beta_{1}+\beta_{2} M_{e}+\beta_{3} \log _{10}\left(R_{e s}\right)+\beta_{4} D_{e}
$$

with coefficients $\boldsymbol{\beta}=\left(\beta_{1}, \beta_{2}, \beta_{3}, \beta_{4}\right)$ of the GMM consisting of the parameters that capture the characteristics of the seismic region and the geological structure. We assume a weakly informative prior Gaussian distribution for $\boldsymbol{\beta}$ (for more details about BHM modeling see Rahpeyma et al. 2018, 2019). We note that we assume self-similar magnitude scaling as deviation from self-similarity of peak parameters is observed at magnitude ranges well above those in our dataset. For the same reason, we did not implement a magnitudedependent distance-attenuation term. Thus, we expect this GMM to apply very locally, contrary to the new Bayesian hybrid GMMs that quantify the regional scaling and attenuation of earthquake strong-motion in Southwest Iceland (Kowsari et al., 2019, 2020; Sonnemann et al., 2020).

Here we develop the BHM model for the following ground-motion parameters of interest, peak ground acceleration and pseudo-acceleration response spectrum at oscillator periods $T=0.05,0.1,0.15,0.2,0.25,0.3,0.4,0.5,1.0 \mathrm{~s}$, i.e., within the range of main engineering interests. This range of periods allows us to discuss short, moderate, and long periods. The Markov Chain Monte Carlo (MCMC) scheme we used in Rahpeyma et al. (2018), which relies on the Metropolis steps of Roberts et al. (1997), provides reliable 
estimates of the posterior distribution of the latent parameters, $\boldsymbol{\eta}=(\boldsymbol{\beta}, \boldsymbol{\delta} \boldsymbol{B}, \boldsymbol{\delta} \boldsymbol{S} 2 \boldsymbol{S})$, along with the hyperparameters, $\boldsymbol{\theta}=\left(\tau, \phi_{S 2 S}, \phi_{S S}, \phi_{R}, \Delta_{S S}\right)$, of our BHM model. The MCMC algorithm consists of two steps: (1) The hyperparameters are sampled jointly from the marginal posterior density $\pi(\boldsymbol{\psi} \mid \boldsymbol{y})$ using the Metropolis step of Roberts et al. (1997) in which $\boldsymbol{\psi}$ is a vector of reparametrized hyperparameters by the logarithm function. (2) The latent parameters are sampled jointly from $\pi(\boldsymbol{\eta} \mid \boldsymbol{y}, \boldsymbol{\psi})$. In this Metropolis algorithm, random samples of parameters in hyperparameter level are drawn from a multivariate normal density centered at the previous draw with a covariance matrix $c(-\boldsymbol{H})^{-1}$, where $\boldsymbol{H}$ is the Hessian matrix evaluated at the mode and with $c=2.382^{2} / \operatorname{dim}(\boldsymbol{\psi})$ (Roberts et al., 1997). The Hessian matrix is defined as a square-matrix of second-order partial derivatives of a scalar-valued function (read Rahpeyma et al., (2018) for more details). It should be noted that we first estimated the range parameter of the station term by trial and error and then fixed it at $\Delta_{S 2 S}=60$ meters corresponding to their respective minimum inter-station distances across ICEARRAY I.

\section{Results}

Bayesian inference of hyperparameters: $\theta=\left(\tau, \phi_{S 2 S}, \phi_{S S}, \phi_{R}, \Delta_{S S}\right)$

Contrary to the commonly used classical regression analysis (e.g., mixed-effect regression analysis) designed to decouple the observed ground motion parameters and provide point estimates and confidence intervals of the unknown model parameters, the BHM presents the model parameters in terms of the posterior probability density which describes the uncertainty of the model parameters given the observed data. When a simulation is applied to sample from the posterior distribution the uncertainty of all parameters can easily be assessed. In this study, we initially developed a BHM model for PGA and PSA at oscillator periods $T=0.05-3.0 \mathrm{~s}$. The marginal posterior distributions of the hyperparameters, defined as the variation (i.e., standard deviations) of the event terms $(\tau)$, station terms $\left(\phi_{S 2 S}\right)$, event-station terms $\left(\phi_{S S}\right)$, and the remaining model error and unexplained terms $\left(\phi_{R}\right)$, are shown in Figure 3 and their statistics are presented in Table A1. As one can see in Figure 3, the posterior distributions of the hyperparameters are not reliable at longer periods ( $T>1 \mathrm{~s}$ ) mainly due to low energy of small events at longer periods. Therefore, due to the limited seismic energy of small earthquakes at long periods, we focus on the interpretation of our results at lower periods $(T \leq 1 \mathrm{~s})$.

The marginal posterior densities appear unimodal with varying amplitudes and range of uncertainties. In particular, the posterior distributions of the event term $(\tau)$ variability exhibit symmetric and unimodal densities with similar posterior mean values in the range of $\tau \sim 0.19-0.24$ in base-10 logarithm (0.45-0.55 in natural logarithm) and posterior standard deviations of $\sigma_{\tau} \sim 0.007-0.008$ (0.016-0.018 in natural logarithm) over the short and moderate period range. The posterior distributions of the event-station term $\left(\phi_{S S}\right)$ variability show a similar tendency, although they are narrower with lower posterior mean values at shorter periods $(<0.30 \mathrm{~s})\left(\phi_{S S} \sim 0.106-0.125\right.$ and $\sigma_{\phi_{S S}} \sim 0.003-0.004$ in base-10 logarithm and $\phi_{S S} \sim 0.24-0.29$ and $\sigma_{\phi_{S S}} \sim 0.007-0.009$ in natural logarithm). Whereas it noticeably weakens at longer periods (lower frequencies), likely because the energy of the small events reduces at lower frequencies. The solutions for the station term $\left(\phi_{S 2 S}\right)$ 


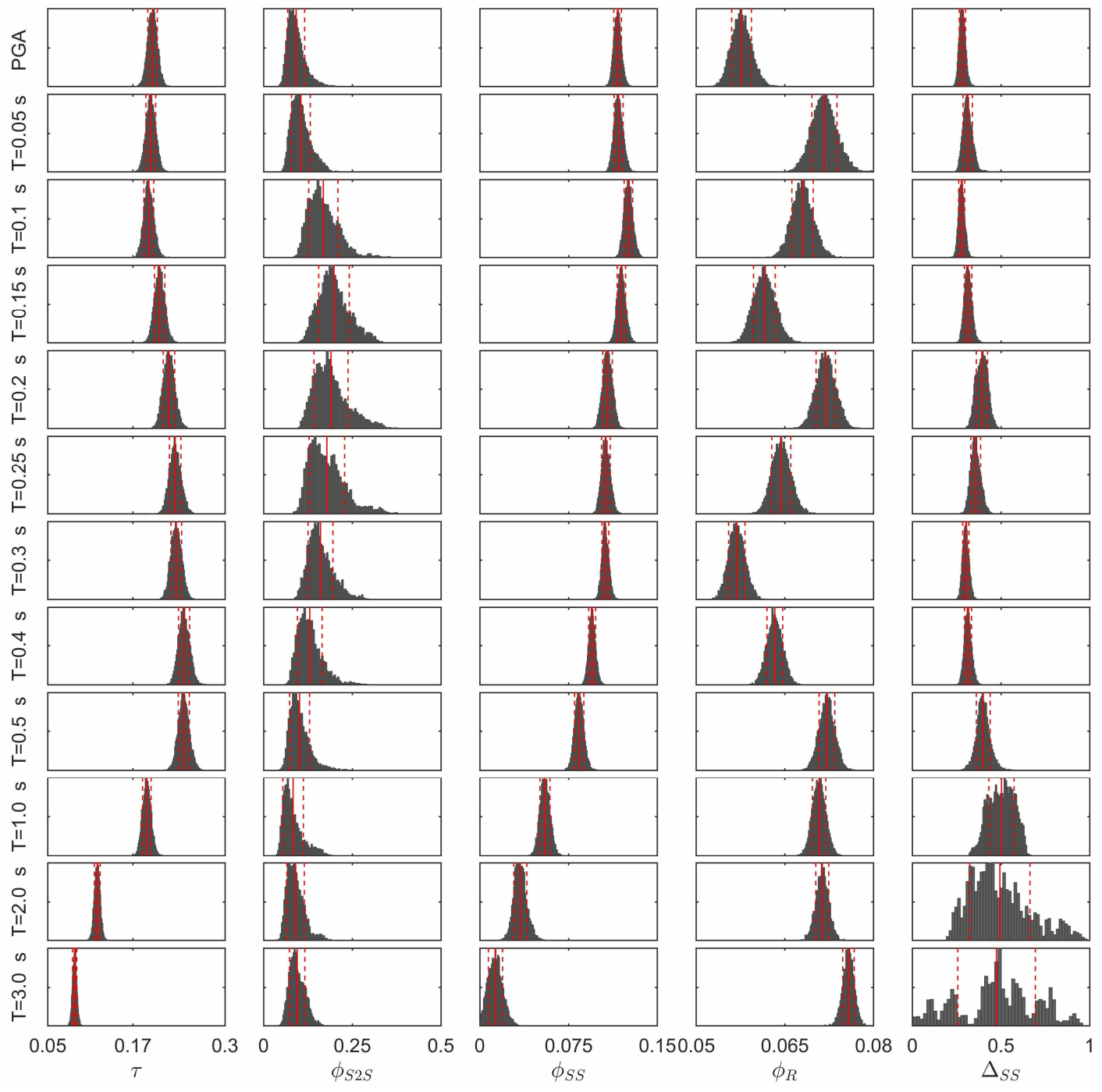

Figure 3. Posterior probability density functions of hyperparameters $\boldsymbol{\theta}$, for different periods, based on Markov chain Monte Carlo simulations of four chains.

The distribution of the standard deviations for event $(\tau)$, station $\left(\phi_{S 2 S}\right)$, event-station $\left(\phi_{S S}\right)$, and unexplained $\left(\phi_{R}\right)$ terms, as well as for the range parameter $\left(\Delta_{S S}\right)$ of the event-station terms are shown left-to-right. The red solid and dashed lines show posterior mean and $16-84 \%$ posterior percentile, respectively.

variability tend to be skewed to the right for the different periods, with a higher level of uncertainty compared to the other terms ( $\sim 6$ times larger). It is of note that the posterior mean, as well as the posterior standard deviation, appear to be particularly broader in the narrow period range of $T=0.1-0.3 \mathrm{~s}$. Then, as shown in Figure 3, the posterior distributions of the unexplained terms variability $\left(\phi_{R}\right)$ remains relatively low in terms of posterior means ( $\phi_{R} \sim 0.06-0.07$ and $\phi_{R} \sim 0.14-0.16$ in base-10 and natural logarithm, respectively) over the short and moderate periods ( $T \leq 1.0 \mathrm{~s}$ ). We also note that the posterior distributions of the range parameter for the event-station terms $\left(\Delta_{S S}\right)$ have relatively low and similar variability $\left(\sigma_{\Delta_{S S}} \sim 0.02-0.04 \mathrm{~km}\right)$ for the period range less than $1.0 \mathrm{~s}$.

Posterior correlations of the hyperparameters at different periods indicate that they follow mostly a similar trend at the twelve oscillator periods. First and foremost, the interstation variation $\left(\phi_{S 2 S}\right)$ appears not to be significantly correlated with any of the other 
hyperparameters. We are therefore confident in the results for the station terms to be unaffected by event characteristics. On the other hand, the inter-event term variability shows a low negative correlation with the other variabilities. The strongest posterior correlation is found between the event-station variation $\phi_{S S}$ and event-station range parameter $\Delta_{S S}$ as expected $(\sim 0.60)$.

\section{Bayesian inference of latent parameters: $\eta=(\delta B, \beta, \delta S 2 S)$}

The event terms i.e., the inter-event residuals $\left(\delta B_{e}\right)$, can be used to evaluate the relative influence of each earthquake on the observed ground motion levels. The overall pattern of the posterior distribution of the individual earthquake event terms that emerges from an examination of the residual trend is that the posterior distribution of the event terms for each data point (each event recorded at multiple stations) shows a symmetric and unimodal distribution. At all periods, the mean of $\delta B_{e}$ falls very close to zero and is associated with considerably lower variability at longer periods, likely due to small events having less energy at longer periods, and no significant trend with seismic parameters was found. It should be noted that the posterior correlation between the event terms is found to be relatively low.

The station terms, $\delta S 2 S$, indicate to what extent the ground motion amplitudes can be expected to be consistently either higher or lower than what the GMM predicts. Therefore, the station terms can be used to scale the GMM to a site-specific prediction (e.g., Rodriguez-Marek et al. 2013; Kotha et al. 2016; 2017a-b). The posterior probability distributions of the station terms are Gaussian and well-constrained as is evident from their narrow posterior intervals which are associated with small posterior standard deviations (Figure 4). However, there is a noticeable increase in the posterior variability (i.e., station term's posterior standard deviation, the width of the distribution) of the station terms for the period range of 0.1-0.3 $\mathrm{s}$ in which the standard deviation is about 0.06-0.07, that is, $\sim 2.5$ times larger than the posterior standard deviation for PGA, and the longer periods ( 0.03-0.04). Increase in the posterior variability of the individual station terms appears to be associated with an increase in the station-to-station standard deviation, $\phi_{S 2 S}$. This was to be expected from the previous observation that overall, the standard deviation of the station terms increases in this period range. Evidently, Figure 4(c-g) highlights that while stations IS609, IS611, and IS612 tend to have a reduction at a period range of 0.1-0.3 s, the stations characterized as lava-rock stations amplify. For example, stations IS604 and IS611 show the lowest relative station terms of $-0.08 \pm 0.03$ base-10 logarithmic units for PGA while at period $0.25 \mathrm{~s}$ station term for IS604 $\left(\delta S 2 S_{4}\right)$ amounts to $0.13 \pm 0.06$ and station term for IS611 $\left(\delta S 2 S_{9}\right)$ becomes $-0.23 \pm 0.06$. Stations IS609, IS611, and IS612 are the exception from the above. Station IS609 is located on older bedrock while the other stations are located on a post-glacial lava-rock layer on top of a sedimentary layer according to the logs of shallow boreholes across the Hveragerði. A high-temperature geothermal area is in

the central part of the town (cf. geothermal map of Hveragerði) where station IS611 is located, and as a result that station cannot be regarded as a typical station on the lava rock. Finally, station IS112 is located in a deep basement where the effects of the surface lava layer may be less apparent than at other sites. 
In contrast to the variation between station terms $\left(\delta S 2 S_{S}\right)$ at different periods, the interstation residuals all show similar trend across the period range, which highlights the stability of the site effects across ICEARRAY I. As can be seen in Figure 4, some stations have significantly positive (amplifying) or negative (de-amplifying) influence on ground motion parameters across all frequencies while for some other there is a meaningful difference between shorter and longer periods. For instance, station IS601 $\left(\delta S 2 S_{1}\right)$ has an amplifying effect while station IS609 $\left(\delta S 2 S_{8}\right)$ has mostly de-amplifying effects at different frequencies, and stations such as IS603 $\left(\delta S 2 S_{3}\right)$ and IS604 $\left(\delta S 2 S_{4}\right)$ switch from deamplifying to amplifying effects at higher to lower frequencies, respectively. A detailed look at Figure 4 reveals that station terms at station IS602 $\left(\delta S 2 S_{2}\right)$ have the lowest amplitudes as well as the lowest variation at different frequencies. Therefore, station IS602 appears to be a consistent benchmark.
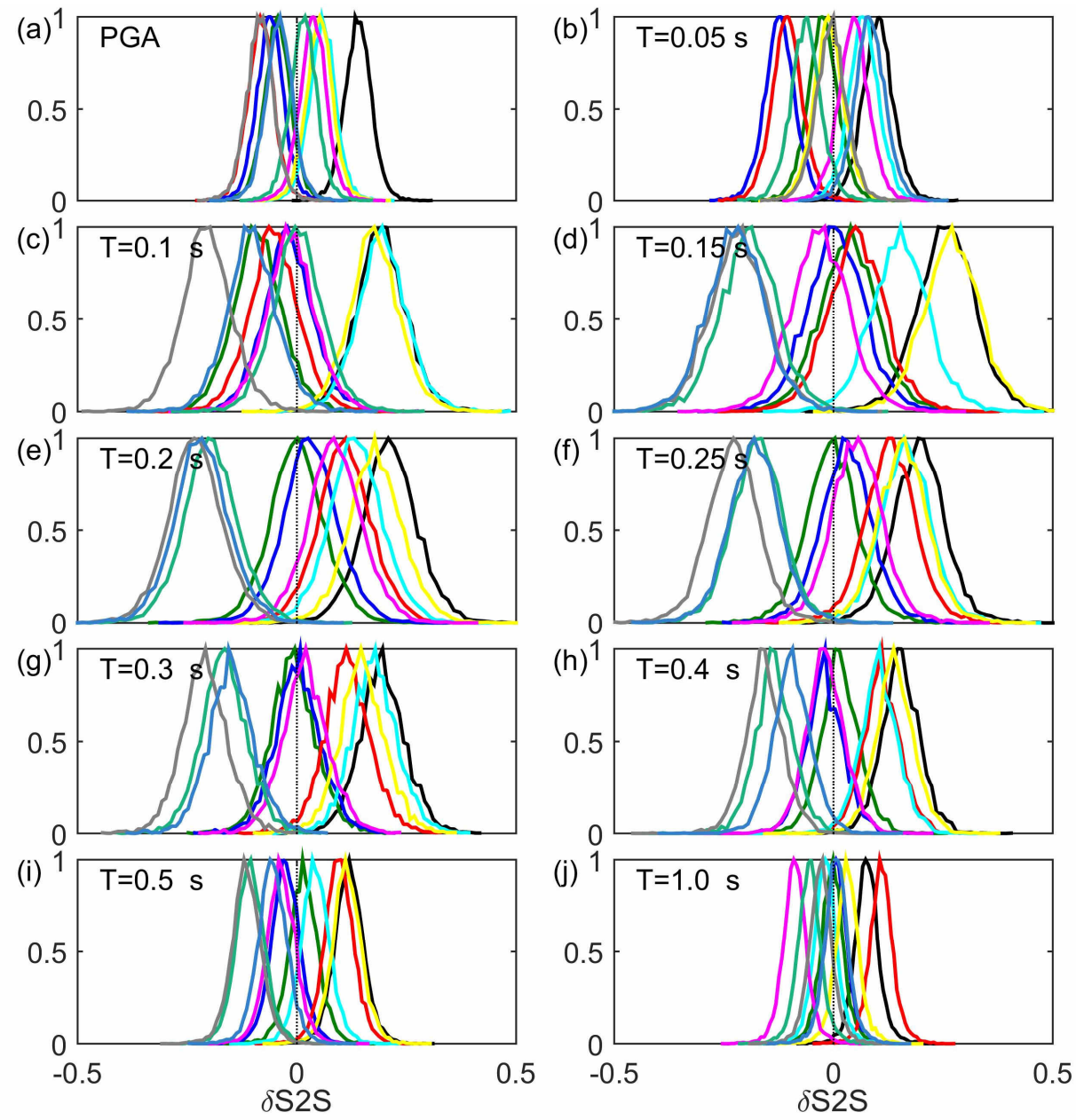

\begin{tabular}{|rrrr}
\hline IS 601 & IS602 & IS603 & IS604 \\
IS 607 & IS605 \\
IS608 & IS609 & IS611
\end{tabular}

Figure 4. (a-j) Posterior distributions of station terms, $\boldsymbol{\delta} \boldsymbol{S} 2 \boldsymbol{S}$, for the 10 different strong-motion stations of ICEARRAY I (indicated by distinct colors) at different periods.

Stations IS609 (pink), IS611 (black), and IS612 (yellow) do not show typical lava-rock station characteristics and are therefore considered as reference stations; A notable increase in standard deviation of stations terms can be found at periods of 0.1-0.3 s, indicating resonance of the soil structure in this range of periods. The dotted black line indicates the zero baseline. 


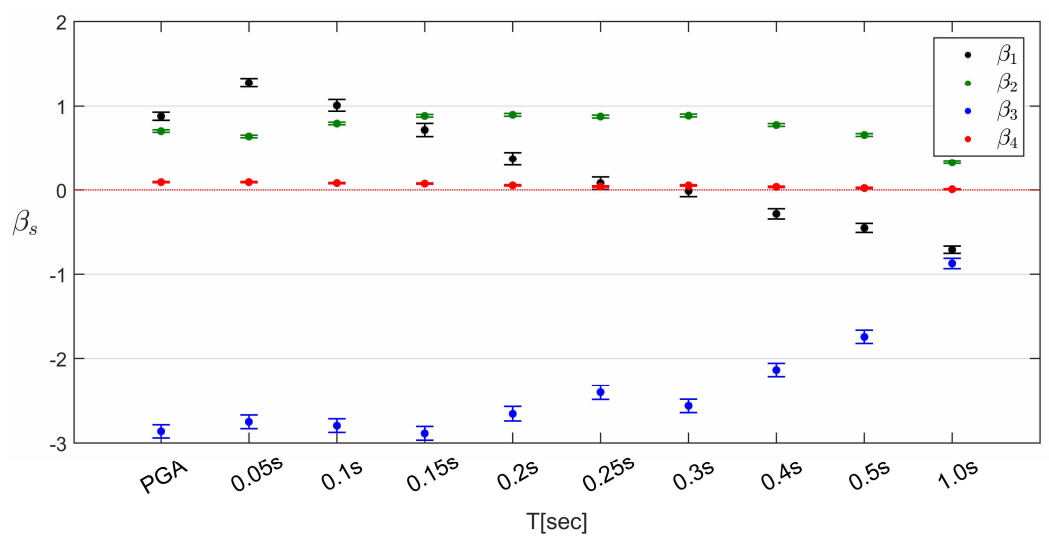

Figure 5. Comparison of the mean values and standard deviations of the model regression coefficients $\left(\beta_{s}\right)$ for PGA and the different spectral periods. $\beta_{1}$ : the constant coefficient; $\beta_{2}$ : magnitude scaling coefficient; $\beta_{3}$ : geometric attenuation coefficient; and $\beta_{4}$ : depth scaling coefficient.

Finally, as can be expected for seismic motions recorded over a relatively small area compared to the source-station distance, there is a very high overall positive posterior correlation between station terms $(>0.90)$ at the twelve oscillator periods. The highest correlation is found between IS602, IS603, IS604, IS605, and IS607, which are the subgroup with the smallest interstation distances, all located in the northwestern corner of the array. The very highest correlation is then found for stations IS603, IS604, and IS605 that form the densest part of the array, with interstation distances of only 54 to 114 meters. Station IS611 $\left(\delta S 2 S_{9}\right)$ sits in the middle of the array and has a similar correlation to all stations, while the cross-correlations between remaining stations are lower.

\section{Residual analysis}

Residual analysis is generally used to evaluate the validity of the assumptions of statistical models and may be employed as a tool for model selection. In this study, the BHM is found to be a reliable tool to obtain the model residuals conditioned on the latent parameters $\boldsymbol{\beta}$, i.e., the regression coefficients; $\beta_{1}$ : the constant coefficient; $\beta_{2}$ : magnitude scaling coefficient; $\beta_{3}$ : geometric attenuation coefficient; and $\beta_{4}$ : depth scaling coefficient of the defined GMM (represented by $\mu_{e s}$ ). The analysis met the convergence statistical criteria and resulted in reasonably low posterior standard deviations of the $\beta$ 's for the ICEARRAY I dataset. The posterior densities of the regression coefficients are found to be symmetric and unimodal for all the coefficients over the range of periods (for the tabulated statistical results see Table A3). Besides, the posterior distributions of the regression coefficients allow us to determine the coefficient of variation $(\mathrm{CV})$, defined as the ratio between the posterior standard deviation and the posterior mean of the model coefficients (i.e., $\sigma / \mu$ ) and is a simple measure of relative dispersion. The results confirm the reliability of the regression coefficients as they are generally much smaller than 1.96 (i.e., $<2 \sigma$ for a Gaussian distribution).

In order to compare the regression coefficients' behavior at short, moderate, and long periods we plot in Figure 5 the posterior coefficients error bars (i.e., posterior mean and standard deviations) for PGA and PSA at each of the selected periods. The results reveal 

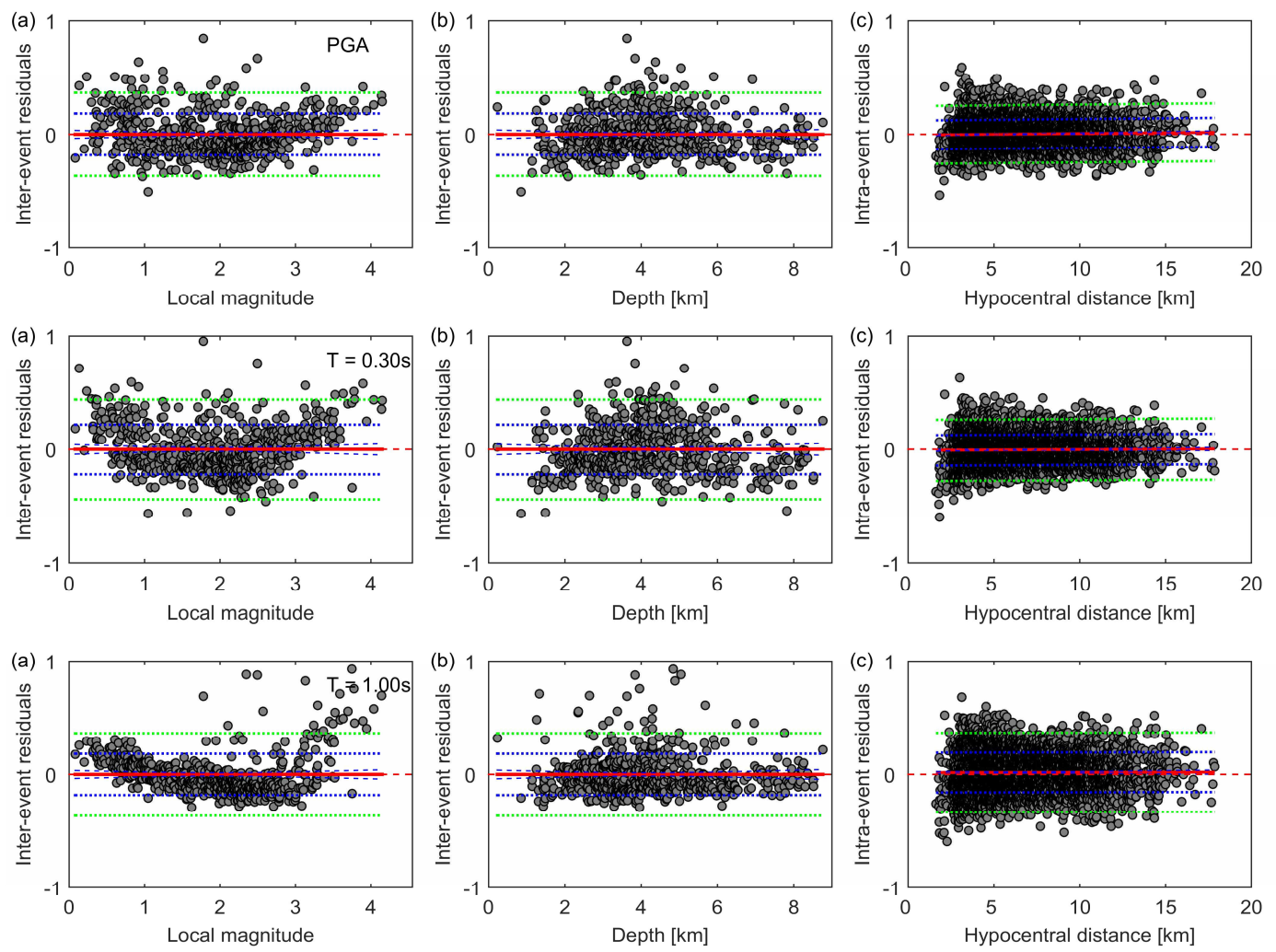

Figure 6. Inter-event (a-b) and intra-event residuals (c), plotted against moment magnitude, depth and hypocentral distance, respectively, for PGA (top) spectral acceleration at $T=0.30 \mathrm{sec}$ (middle) and $T=1.0 \mathrm{sec}$ (bottom). The red thick, blue dashed, blue dotted, and green dotted lines show the sample regression lines, 95\% confidence limits for the ordinate to the true regression lines, regression line \pm 1 and \pm 2 standard deviations, respectively. The figure shows the posterior mean of the inter-event residuals while the intra-event residuals are found by subtracting the GMM, the inter-station and inter-event residuals, using their posterior means, from the observations.

that the depth coefficient $\left(\beta_{4}\right)$ is generally insignificant compared to the other parameters. Conspicuously, the magnitude scaling $\left(\beta_{2}\right)$ as well as the distance coefficient $\left(\beta_{3}\right)$ of the GMM show relatively stable level over short to moderate range of periods. This clearly highlights that the attenuation of high frequency (e.g., PGA) and short period PSAs is strongly dependent on magnitude and distance (Campbell, 1981; Kotha et al., 2018). We also observed that strong ground motions attenuate rapidly with distance and the $\beta_{3}$ values, which are sometimes assumed to be -1 based on the simple theory of geometric attenuation, are found to be lower at the longer periods (see Figure 5 and Table A3). It is worth mentioning that the descending pattern of $\beta_{3}$ with increasing period is also observed and reported by other researchers using Icelandic strong motion data sets (e.g., Ornthammarath et al. 2011 and Kowsari et al. 2020).

As defined in Equation (1), the total residual includes the inter-event and intra-event effects (i.e., $\Delta=\delta B_{e}+\delta W_{e s}$ ) (Al Atik et al., 2010). The intra-event residual can be determined by additionally removing the individual event terms $\left(\delta B_{e}\right)$ from the total residuals. Moreover, the BHM allows us to determine inter-station terms, i.e., inter-station residuals $\left(\delta S 2 S_{S}\right)$. In Figure 6, the inter-event and intra-event residuals of the model are shown for PGA and the response spectrum at $0.3 \mathrm{~s}$ and $1.0 \mathrm{~s}$. No meaningful trends of the 
inter-event or intra-event residuals are visible with respect to the local magnitude, hypocentral distance, and depth. Moreover, their distribution vs. back-azimuth shows no sign of trend (results not shown). A detailed look at Figure 6 revealed that the inter-event residuals show less variability at lower frequencies (also see Table A1 for comparing $\boldsymbol{\tau}$ ). In general, the unbiased distribution of the inter-event and intra-event residuals in this study indicates that the applicability of the used GMM in this study.

\section{Discussion}

\section{Contribution of source, path, and site effects variabilities}

One of the most useful features of the BHM is that it allows us to decompose the variability in the residuals such that the respective contributions of source, path, and site effects can be determined. In the BHM formulation, $\tau$ presents differences of one particular event from the mean given by the GMM for this particular event, while $\phi_{S 2 S}$ and $\phi_{S S}$ are site-to-site and record-to-record variabilities, respectively (Kuehn and Scherbaum, 2015, 2016; Rahpeyma et al., 2018, 2019; Strasser et al., 2009). The relative comparison of the standard deviations of inter-event $(\tau)$, inter-station $\left(\phi_{S 2 S}\right)$, event-station $\left(\phi_{S S}\right)$, and unexplained effects and other unaccounted factors $\left(\phi_{R}\right)$ are presented graphically in Figure 7 and numerically in Table A1. A first look at Figure 7 reveals that the inter-event standard deviation has the greatest contribution to the total standard deviation over the range of periods of this study. Upon further scrutiny, a generic high aleatory variability (commonly called sigma, $\sigma$ ) is observed in the period range of 0.1-0.3 s (see Figure 7a). While the event-station and unexplained standard deviations show a rather constant contribution in this period range, the inter-station variability shows a considerable boost in the range of moderate periods $(0.1 \mathrm{~s} \leq T \leq 0.3 \mathrm{~s})$, which reflects the greater level of disagreement in the station terms at these periods (see Figure 4). In particular, at high frequencies (e.g., PGA and spectral response at $T=0.05 \mathrm{~s}$ ), the variabilities of the inter-event, inter-station, eventstation, and unexplained effects appear to have a constant contribution of $\sim 60 \%, \sim 15 \%$, $\sim 20 \%, \sim 5 \%$, respectively (see Figure $7 \mathrm{~b}$ ). However, for the period range of $0.1-0.3 \mathrm{~s}$, the contribution of inter-station variability is seen to noticeably increase from $\sim 20 \%$ to $\sim 40 \%$

with the corresponding reduction in inter-event variability from $\sim 60 \%$ to $\sim 40 \%$. The other variabilities remain unchanged indicating that the sole reason is that an anomalously large station-to-station variability suddenly overrides the inter-event variability and then only in this period range. At longer periods the inter-event standard deviation evidently decreases to the same level of variability while the inter-station variability increases. This is a direct manifestation of the station terms in Figure 4 in this period range diverging from their otherwise fairly constant values. The physical reason for this is discussed further below, but at this point, we note that this divergence is likely because at those periods the excitation matches the fundamental period of oscillation of the underlying soil structure and resonance occurs on most of the stations on lava rock, and to varying degrees (see Rahpeyma et al., 2016), as becomes evident from the dispersion of the station terms. In fact, while it may appear in Figure 4 that some station terms decrease (i.e., IS609, IS611, IS612) at these frequencies, they actually do not. They remain stable while the other station terms increase, but the plots are shown relative to the average $\delta S 2 S$ at that given oscillator period. 

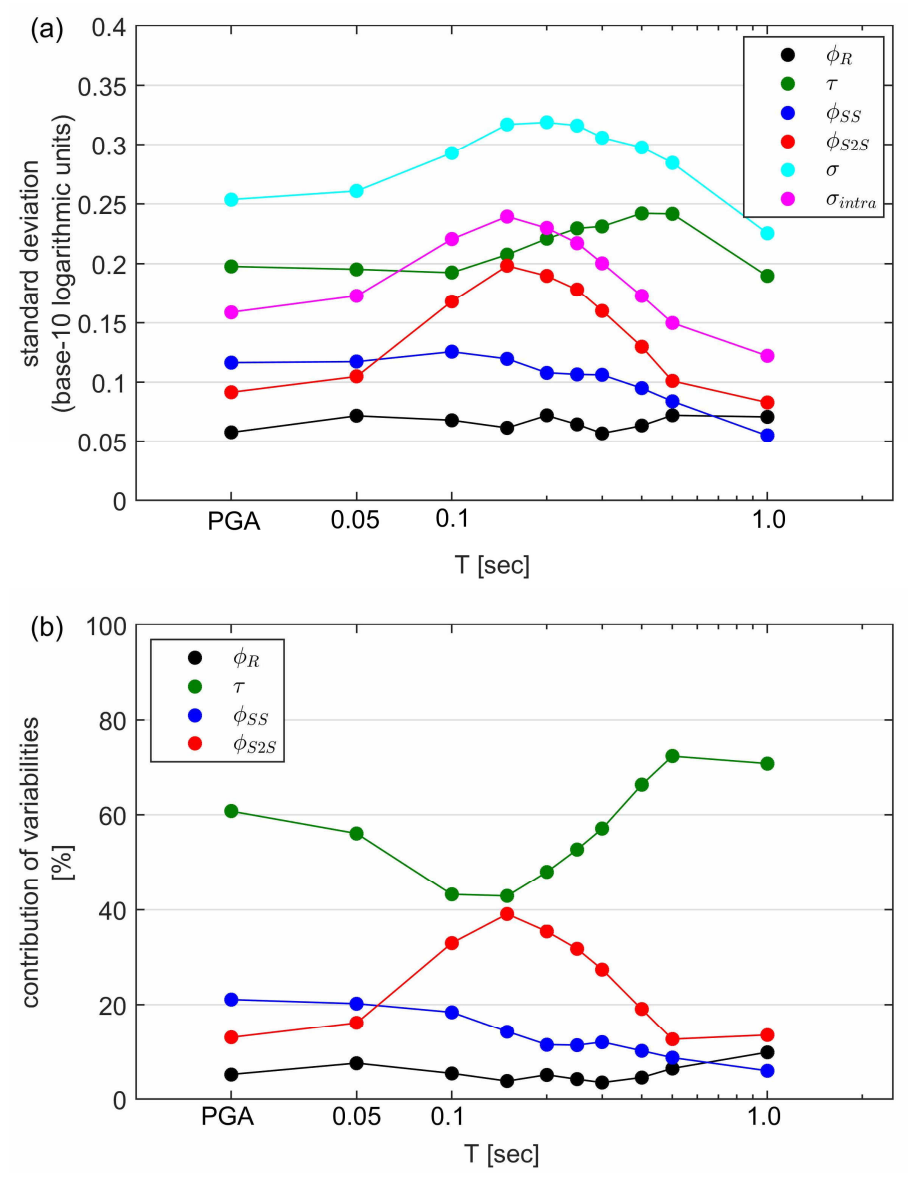

Figure 7. (a) Comparison of inter-event $(\tau)$, inter-station $\left(\phi_{S 2 S}\right)$, event-station $\left(\phi_{S S}\right)$, and unexplained $\left(\phi_{R}\right)$ standard deviations along with the intra-event standard deviation $\left(\sigma_{\text {intra }}\right)$ and the total $(\sigma)$ for PGA and spectral accelerations at different oscillator periods. (b) The same comparison, now in terms of contribution in percentages to the total $(\sigma)$.

In the BHM modeling, the intra-event residuals account for path and site variability and consist of the inter-station, the event-station, and the unexplained effects variabilities (i.e., $\phi=\sqrt{\phi_{S 2 S}^{2}+\phi_{S S}^{2}+\phi_{R}^{2}}$ ). Thus, the total standard deviation includes the inter-event standard deviation, $\tau$, and the intra-event standard deviation, $\phi$, i.e., $\sigma=\sqrt{\tau^{2}+\phi^{2}}$. As presented in Table A1, the intra-event variabilities have relatively larger values within the period range of $T=0.1-0.3 \mathrm{~s}$. Furthermore, the total standard deviation decreases with increasing period which is in contrast to what is usually observed (e.g., see Ambraseys et

al. 2005; Akkar and Bommer 2010; Ornthammarath et al. 2011). This is to a great extent due to using aftershocks of small local magnitudes within the range of $M_{\mathrm{L}} 0.42-4.75$. In addition, the recorded seismic data has sampled a relatively small part of the crust in the microseismic region on its way to the dense array which has a small aperture compared with the hypocentral distances to stations. This descending pattern of sigma was also reported by Ornthammarath et al. (2011) in which Icelandic strong ground motion data of six SISZ earthquakes of magnitudes larger than 5 recorded at 31 different stations (81 strong-motion records in total) were used to investigate the source of the variability. Ornthammarath et al. (2011) argued that the geological features of Iceland could possibly explain the low standard deviation (sigma) at longer periods. In contrast to populated parts 
of Europe or California, no deep alluvium soil deposits are underlying any sizeable urban areas in Iceland. As a result, basin and valley effects are nonexistent in Icelandic strongmotion data. They also mentioned that low standard deviation at longer periods could be associated with the data set of which the recordings are collected from a small geographical area and a restricted set of stations. Finally, it should be noted that the total standard deviations reported for local empirical and theoretical GMMs that have been calibrated either exclusively, or to a great extent, to strong-motion data from South Iceland are in good agreement with our findings in this study (e.g., $0.17-0.22$ from Ornthammarath et al., 2011; 0.18 - 0.25 from Kowsari et al., 2020; and 0.281 from Sonnemann et al., 2020). In contrast, the regional European GMMs that have been developed from data in other regions and used for probabilistic seismic hazard assessment for Iceland show considerably larger variability (e.g., 0.32 - 0.56, see Ambraseys et al. 2005).

The specific standard deviations give us the chance to quantitatively estimate to what extent the respective earthquake source, path, and site effects contribute to the overall variability of ground motion recorded across the ICEARRAY. In particular, estimation of the station-to-station variability makes it possible to approximate so-called single-station standard deviation (Al Atik, 2010), which results in more accurate PSHA calculations by avoiding double counting of some parts of the variability (Atkinson, 2006). Hence, during recent decades, many researchers have focused on the effect of single-station sigma by relaxing the ergodic assumption (Chen and Tsai, 2002; Atkinson, 2006; Lin et al., 2011; Rodriguez-Marek et al., 2011, 2013; Chen and Faccioli, 2013; Kuehn et al., 2015, 2016; Ktenidou et al., 2018). To obtain the single-station standard deviation we either need a station-specific dataset or propose a non-ergodic model. It should also be noted that allowing the standard deviation to vary between stations should not be the general assumptions unless there is sufficient data to estimate either empirically, theoretically, or numerically the variabilities. In general, the event-corrected single-station standard deviation $\phi_{S S}$ for the entire dataset can be computed by averaging over all the stations and attributing equal weight is to each of them. Then, by assuming that $\delta B_{e}$ and $\delta W_{e s}$ are statistically independent the so-called single-station standard deviation (sigma) will be calculated as $\sigma_{S S}=\sqrt{\tau^{2}+\phi_{S S}^{2}+\phi_{R}^{2}}$. However, the multilevel formulation of the BHM model presented in this study, allows us to directly separate the overall ground-motion variability into inter-event $(\tau)$, station-to-station $\left(\phi_{S 2 S}\right)$, record-to-record $\left(\phi_{S S}\right)$, and unexplained/unmodeled $\left(\phi_{R}\right)$ components. This makes it possible to estimate the singlestation sigma. Figure 8 compares different component of the variabilities for PGA using strong-motion dataset from different regions with different surface geology. Namely, Rodriguez-Marek et al. (2011) used a subset of data from the KiK-net network in Japan with $4<M_{\mathrm{w}}<7.5$; Lin et al. (2011) implemented a large dataset from Taiwan with $3.9<$ $M_{\mathrm{w}}<6.3$; Ornthammarath et al. (2011) used six mainshocks with $M_{\mathrm{w}}>5$ recorded in south Iceland; and Ktenidou et al. (2018) used accelerometric data from the well-studied valley EUROSEISTEST in northern Greece to investigate ground motion uncertainty and variability.

One of the important results drawn from the previous studies is that in empirical GMMs, the inter-event variability is generally lower than the intra-event variability. However, in this study, as presented in Table A1 and Figure 7a only for the range of periods $0.1 \leq T \leq$ 


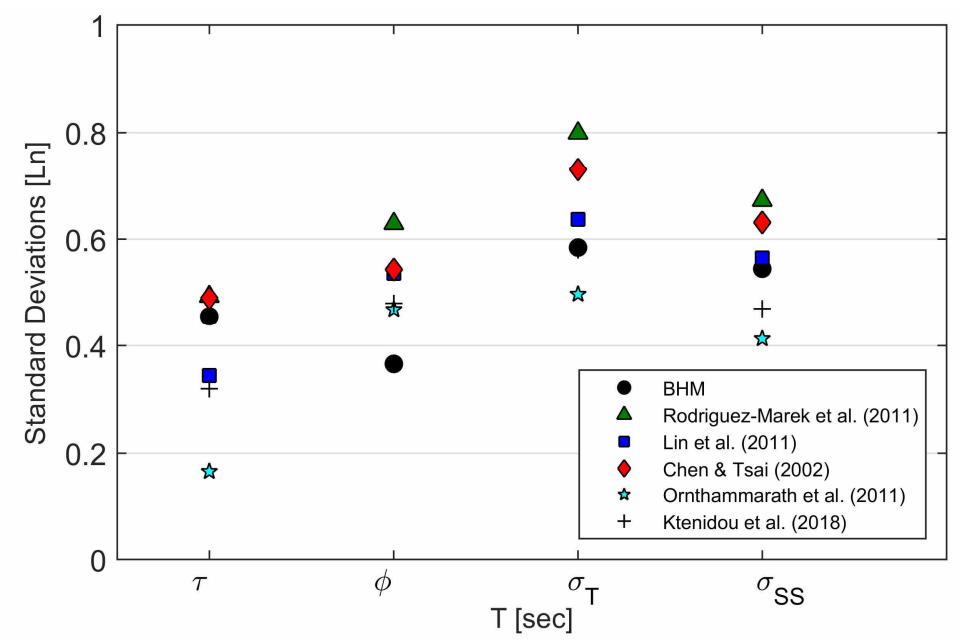

Figure 8. Comparison of the results of this study with corresponding results from published studies. All values pertain to PGA and are natural logarithms. $\tau$ is inter-event standard deviation, $\phi=\sqrt{\phi_{S S}^{2}+\phi_{S 2 S}^{2}+\phi_{R}^{2}}$ is intra-event standard deviation; $\sigma_{T}=\sqrt{\phi^{2}+\tau^{2}}$ is total standard deviation, and $\sigma_{S S}=\sqrt{\tau^{2}+\phi_{S S}^{2}+\phi_{R}^{2}}$ is single-station standard deviation.

$0.2 \mathrm{~s}$ the inter-event variability $(\tau)$ is lower than intra-event variability $\left(\sigma_{\text {intra }}\right)$. This is most probably due to the uniform site conditions over the ICEARRAY I and closely spaced recording stations compared to the large number of earthquakes arriving at the densely located recording stations from multiple azimuths and at various distances. In addition, some studies (e.g., Lee et al. 1998; Douglas and Gehl 2008) suggest that the inter-event variability could be higher at short periods than at long periods. Lee et al. (1998) addressed this effect by observing that at short periods (i.e., high frequencies) the amplitudes of ground motion are much more sensitive to focusing, defocusing, or another source heterogeneous process, while, at longer periods, the geological structure is dominant for long-period waves. In addition, at very long periods ground-motion amplitudes are primarily governed by the seismic moment. Moreover, it has been well known that earthquake source parameters such as the stress drop control the high-frequency source spectral levels (e.g., Brune, 1970; Papageorgiou and Aki, 1983), a theoretical fact that lately has been incorporated as a proxy for source complexity or variability effects in empirical GMMs (e.g., Kotha et al., 2017b). Finally, it should be noted that the SISZ has been the source of many destructive events in the past and is believed to be capable of producing main shocks of around magnitude 7 (Einarsson, 1991; 2008). However, this study uses aftershocks, and for which the magnitude range is significantly lower (i.e., $M_{L}<5.0$ ) than magnitudes considered in seismic hazard analysis. Furthermore, using only aftershocks from a single earthquake as well as relatively similar travel paths of the seismic waves could introduce a reduction of variabilities associated with the ground motion amplitudes.

\section{Site-specific characteristics impact on aleatory variabilities}

As mentioned for Figure $7 \mathrm{a}$, the intra-event standard deviation conspicuously enlarges in the period range of $T=0.1-0.3 \mathrm{~s}$, primarily because of increasing inter-station standard deviation over this range of period. Understanding this unusual bump is essential due to the 
importance of characterizing site-to-site variability for probabilistic hazard assessment and also defining practical site classification proxies. To scrutinize site-to-site variability further, we need to explore site-specific characteristics beneath the ICEARRAY I strongmotion stations. Such information is rather sparse; however, comparing Figure 7 and Figure 2, it is clear that the site-specific characteristics shown in Figure 4 play a significant role around the resonant frequency bandwidth of the subsoil structure of the region. As one can see in Figure 4 and Figure 7, close to the resonance frequencies (i.e., 3-4 Hz and 8-9 Hz or $T=0.1-0.3 \mathrm{~s}$ ) the station terms show larger positive values as well as larger associated uncertainties due to the different levels of the resonance phenomenon that most clearly is manifested in stations such as IS604, IS605, and IS608. This feature is apparent across the ICEARRAY stations on lava but to different extents. Such variability over short distances can be expected due to the undulating nature of the surface of lava flows.

Correspondence between peak amplification and peak variability through predominant frequencies was reported by Zhao et al., (2006) for K-Net sites in Japan. They used HVSR ratios for records from the classified K-net sites to establish a site classification index using the mean spectral ratios over a wide range of spectral periods. The findings of this study revealed that site conditions have profound effects on the ground surface motions as soil sites and inappropriate modeling of site effects can introduce large variability into attention models. More recently, Kotha et al., (2018) used $k$-mean spectral clustering technique in order to classify the estimated site-specific effects $\left(\Delta S 2 S_{S}\right)$ for a large number of wellcharacterized K-Net sites. Then, Cauzzi and Faccioli (2018) observed a peak in the sitespecific variability, most likely indicating larger variability around the fundamental resonance period of some of the contributing sites. The results of this study are in accordance with the above studies, confirming that site effects play a significant role in the amplification level at the predominant frequency of the stations and that the inter-station variability reaches its maximum value around its predominant frequency.

Chen and Faccioli (2013) conducted a systematic analysis on different variability components of the ground motion amplitudes recorded by stations mostly located on deep sedimentary soil sites in the Canterbury region of New Zealand. The findings of this study indicated that there is a plausible correlation between site terms $\left(\delta S 2 S_{S}\right)$ and prevailing geological conditions in the site area. In particular, a significant amplification tendency was observed at station where energy focusing effects caused by topography may have occurred. On the other hand, the site amplification factor (i.e., $10^{\delta S 2 S}$ ) of the station classified as engineering bedrock keeps $\sim 1.0$ except for short periods $(T<0.2 \mathrm{~s}$ ). This station sits on the volcanic rock of Banks Peninsula in the Southeast, as an outcrop which appears to have neither amplified nor de-amplified the ground shaking except for very short period. More recently, Ktenidou et al. (2018) used data from the well-studied valley EUROSEISTEST in Greece to investigate different components of ground motion variabilities. The results showed that there is a small peak in site-to-site variability around 0.7-0.8 s, which may indicate greater variability of site terms around some of the sites' dominant resonance period.

Site amplification factor of lava-rock stations on ICEARRAY I 
The determination of site amplification effects is of paramount importance in earthquake engineering applications. Through the BHM station terms, we have the opportunity to quantify the frequency-dependent site amplification function for the lava-soil structure of ICEARRAY I relative to stations showing no signs of site amplification, either on bedrock or having relatively flat horizontal-to-vertical spectral ratios (HVSR) (Rahpeyma et al., 2016). From geological maps and borehole log information (Sæmundsson and Kristinsson, 2005) those latter stations are shown to be located on older bedrock (IS609), and on postglacial lava-rock (IS611, IS612) (see Figure 2). It is of note that station IS611 is located in the central part of the town that is characterized by geothermal activity with an extremely high and localized temperature gradient and thus likely subject to high wave attenuation. Station IS112 is located in a deep concrete basement at the margin of the uppermost lava layer and its recordings indicate only slight, if any, impedance contrast beneath the station, a likely indicator of a thin intercalated soil layer. As a result, stations IS609, IS611, and IS612 do not show similar site response characteristics (i.e., bimodal or broad HVSR amplification curves) comparing to the stations located on lava-rock. Consequently, the average station terms of these three stations have been considered as a reference station term. The relative differences (at a log-scale) between the posterior distribution of station terms for the ICEARRAY I stations located on lava-rock with respect to the average posterior distribution of stations IS609, IS611, and IS612 (i.e., reference stations) are presented in Figure 9. Upon closer scrutiny, the stations located on lava-rock exhibit a notable shift relative to the reference stations at periods of 0.1-0.4 s while at shorter and longer periods the difference between stations is found to be insignificant. The ratio of the lava-station terms to the reference site average station term is presented in Figure 10 and tabulated in Table A4. The relative station terms on lava show a clear peak at periods of 0.1-0.4 s which is a manifestation of the resonance period range of the soil structure, in agreement with previous studies (Rahpeyma et al., 2016). Thus, this ratio establishes the relative amplitudes of wave amplification of the lava-soil structure, shown to be period dependent and having maximum values ranging between 1.5 and 3.0 at 0.1-0.4 s. These frequency dependent normalized station terms thus in fact represent the first quantitative estimates of site amplification factors across the town of Hveragerði that are suitable for application in ground motion modeling and hazard analyses where site effects are specifically being accounted for, with important applications for risk management and urban planning in the town.

\section{Conclusions}

The strong-motion data recorded by the first Icelandic strong-motion array (ICEARRAY I) after the 29 May 2008, $M_{\mathrm{w}} 6.3$ Ölfus earthquake in the south of Iceland exhibits significant and systematic variations in ground-motion amplitudes over very short distances. This unexpected variation is of significance as the ICEARRAY I resides on top of what is believed to be a uniform site condition characterized as "rock", while geological studies indicating that it is Holocene lava rock on top of a sedimentary layer, thus introducing a reversal in the velocity profile, a layering that may be repeated with depth. For the purpose of comprehensively analyzing the strong motion to explain its observed variations, we modeled it using a multi-level Bayesian Hierarchical Model in order to quantify the relative 
(a)

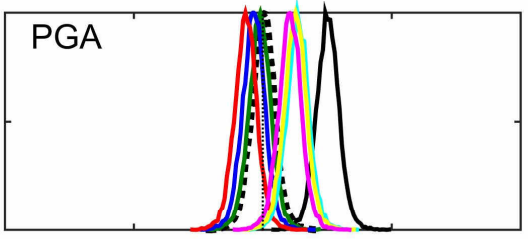

(c)

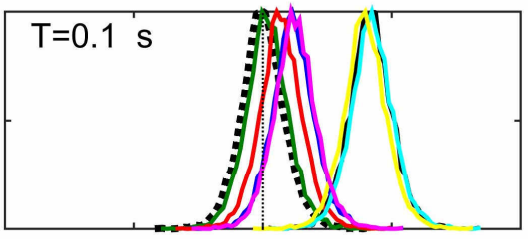

(e)

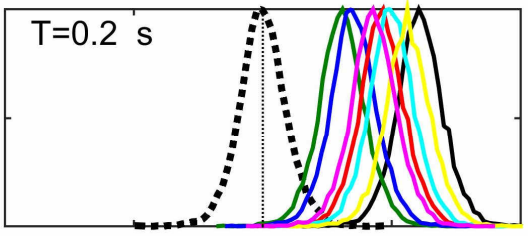

(g)

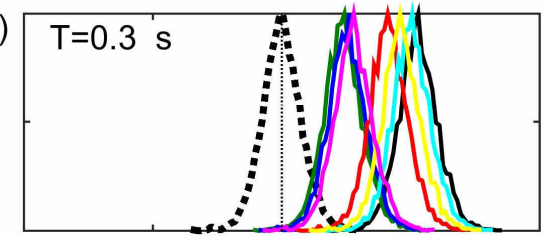

(i)

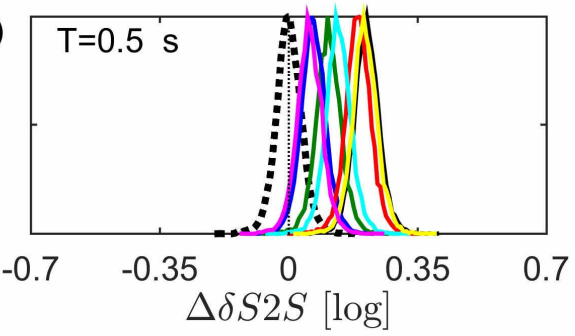

(b)

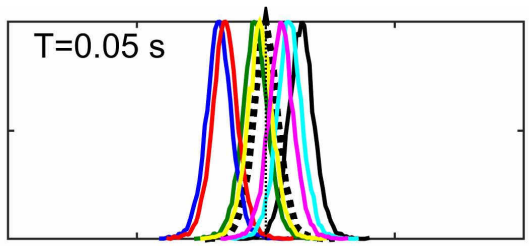

(d)

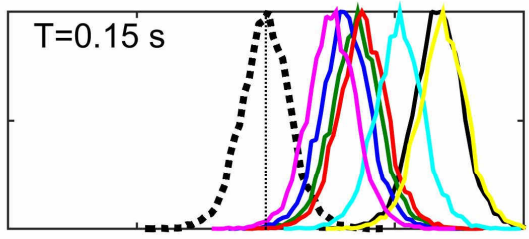

(f)

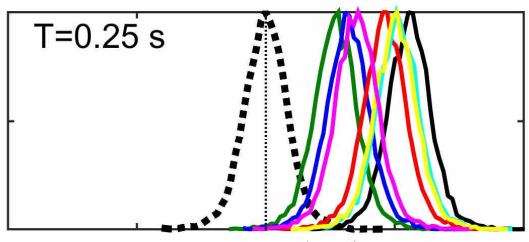

(h)

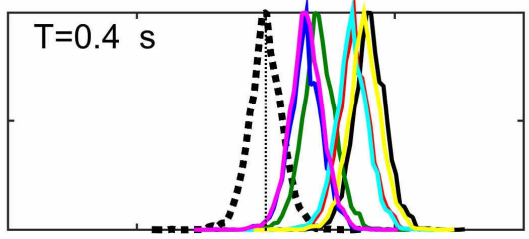

(j)

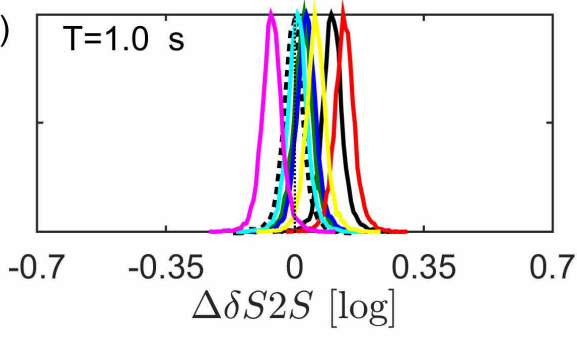

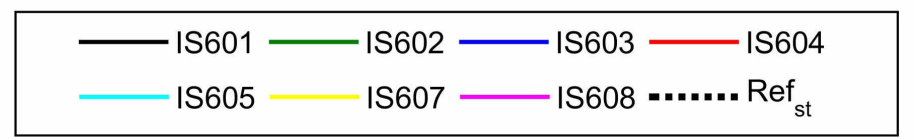

Figure 9. (a-j) Relative differences between the posterior distribution of station terms for the ICEARRAY I strong-motion stations located on lava-rock (color coding for each station) with respect to the posterior distribution of reference station term (black dashed curve), estimated for PGA and PSA at different periods ( $T=0.05-1.0 \mathrm{~s}$ ). The reference station term $\left(\operatorname{Ref}_{\mathrm{st}}\right)$ is defined as the average of the posterior distribution of stations IS609, IS611, and IS612 which are not characterized as typical lava-rock stations. The dotted black line indicates the zero baseline.

contributions of source, site, and path effects to those variations, and splitting the total variability into inter-event and intra-event variabilities, the latter of which is further partitioned into an inter-station term, an event-station term, and an unexplained variability term. Detailed site effect investigation had revealed that there is significant and bimodal peak HVSRs on most of the lava rock stations around periods of $0.3 \mathrm{~s}$ and $0.1 \mathrm{~s}$, respectively, indicating resonance of the soil structure of lava layers with intercalated sedimentary layers. In this study, therefore, we developed a BHM model for PGA and to the 5\% damped PSA at oscillator periods of $T=0.05-1.0$ for the purpose of capturing the station terms as a function of period and developing period-dependent site factors across the ICEARRAY I. 


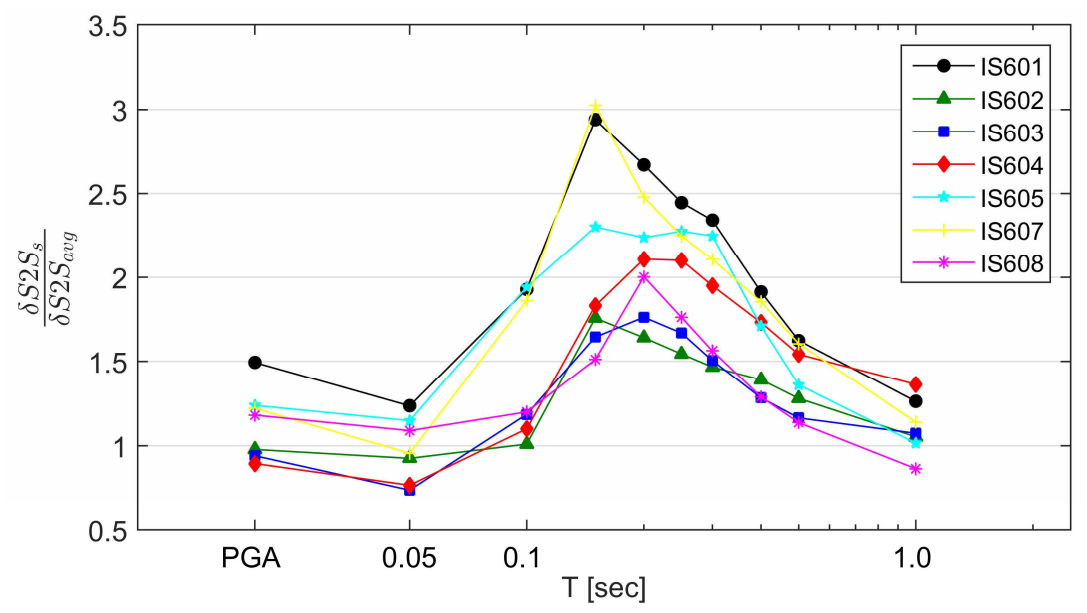

Figure 10. The relative ratio between ICEARRAY I stations (indicated with different color codes and markers) located on lava-rock and the average of station terms located on the rock considered as reference station (i.e., IS609, IS611, and IS612).

The results showed that the inter-event standard deviation contributes the greatest to the total standard deviation over the range of periods of this study, in agreement with previous studies, and does so rather uniformly across the period range. The underlying cause is likely the wide range of event magnitudes, epicentral distances, and azimuthal directions from which the seismic waves approach the array that characterize the recordings. More importantly, the results clearly show a significant increase in the intra-event standard deviation in the period range of 0.1-0.3 $\mathrm{s}$ that is completely driven by a considerable increase in the inter-station standard deviation i.e., the scatter of the station terms. This is due to the large increase in the individual station terms for some of the stations residing on lava rock (and not all stations, hence the increased associated variability) at those periods, as expected from previous HVSR studies. This is undoubtedly caused by the soil structure under the stations going into varying levels of resonance at those periods, thereby increasing the site amplification in this period range, and the different levels of amplifications observed in the modeling results for different stations contributing to the increased uncertainty of the station terms. We then establish the period-dependent site amplification factors for the lava-soil structure relative to stations showing no signs of site effects i.e., either on bedrock or having reasonably flat site amplification (HVSR). The relative site factors are found to be period dependent with maximum values of 1.7-3 in the period range of 0.1-0.3 s. In this way, we provide an important contribution to our improved understanding of the key factors that affect the variation of seismic ground motions across a relatively small area (the array has an aperture of $\sim 1.9 \mathrm{~km}$ and a minimum inter-station distance of $\sim 50 \mathrm{~m}$ ). By modeling the variations of strong motions across the array, quantifying individual station terms, and showing how different physical phenomena contribution to the variations at different frequencies, we believe that the results have important practical implications for improving the accuracy of earthquake hazard assessment on a local scale, which in turn can contribute to a more refined seismic risk assessment and engineering decision making. 


\section{Declaration of conflicting interests}

The author(s) declared no potential conflicts of interest with respect to the research, authorship, and/or publication of this article.

\section{Funding}

The author(s) disclosed receipt of the following financial support for the research, authorship, and/or publication of this article: This work was supported by the Icelandic Center for Research (Rannís) Grant of Excellence (grant no. 141261-051/52/53), Postdoctoral Research Associate Grant (grant no. 196407-051), Energy Research Fund of Landsvirkjun, the National Power Company of Iceland Grant 2019-2020 (grant no. NÝ R03-2019), and an Icelandic Road and Coastal Administration Research Grant 2019-2020. The instruments of ICEARRAY I were funded through a Marie Curie Re-integration Grant in 2006 and of ICEARRAY II by Rannís in 2008. The second author's work was also partially funded through the TURNkey H2020 Project (grant no. \#821046). The second author would like to express his gratitude to the inhabitants of Hveragerði and Húsavík, and their municipalities, for housing the recording equipment and their dedication and support to the ICEARRAY project.

\section{References}

Abrahamson, N. A., and Youngs, R. R., 1992. A stable algorithm for regression analyses using the random effects model. Bulletin of the Seismological Society of America, 82(1), 505-510.

Akkar, S., and Bommer, J. J., 2010. Empirical equations for the prediction of PGA, PGV, and spectral accelerations in Europe, the Mediterranean region, and the Middle East. Seismological Research Letters, 81(2), 195-206.

Al Atik, L., Abrahamson, N., Bommer, J. J., Scherbaum, F., Cotton, F., and Kuehn, N., 2010. The variability of ground-motion prediction models and its components. Seismological Research Letters, 81(5), 794-801.

Ambraseys, N. N., Douglas, J., Sarma, S. K., and Smit, P. M., 2005. Equations for the estimation of strong ground motions from shallow crustal earthquakes using data from Europe and the Middle East: horizontal peak ground acceleration and spectral acceleration. Bulletin of earthquake engineering, 3(1), 1-53.

Atkinson, G. M., 2006. Single-Station Sigma. Bulletin of the Seismological Society of America, 96(2), 446-455. DOI: 10.1785/0120050137

Bessason, B., and Kaynia, A. M., 2002. Site amplification in lava rock on soft sediments. Soil dynamics and Earthquake engineering, 22(7), 525-540.

Bommer, J. J., and Crowley, H., 2006. The influence of ground-motion variability in earthquake loss modelling. Bulletin of Earthquake Engineering, 4(3), 231-248.

Boore, D. M., Joyner, W. B., and Fumal, T., 1997. Equations for estimating horizontal response spectra and peak acceleration from North American earthquakes: A summary of recent work. Seismological Research Letters, 687(1), 128-154.

Borcherdt, R. D., and Glassmoyer, G., 1992. On the characteristics of local geology and their influence on ground motions generated by the Loma Prieta earthquake in the San Francisco Bay region, California. Bulletin of the Seismological Society of America, 82(2), 603-641.

Brandsdóttir, B., Parsons, M., White, R. S., Guðmundsson, Ó., Drew, J., and Thorbjarnardóttir, B. S., 2010. The May 29th 2008 earthquake aftershock sequence within the South Iceland Seismic Zone: Fault locations and source parameters of aftershocks. Jokull: journal of the glaciological and geological societies of Iceland, 60, 23-46. 
Brillinger, D. R., and Preisler, H. K., 1984. An exploratory analysis of the Joyner-Boore attenuation data. Bulletin of the Seismological Society of America, 74(4), 1441-1450.

Brillinger, D. R., and Preisler, H. K., 1985. Further analysis of the Joyner-Boore attenuation data. Bulletin of the Seismological Society of America, 75(2), 611-614.

Brune, J. N., 1970. Tectonic stress and the spectra of seismic shear waves from earthquakes. Journal of geophysical research, 75(26), 4997-5009.

Campbell, K. W., 1981. Near-source attenuation of peak horizontal acceleration. Bulletin of the Seismological Society of America, 71(6), 2039-2070.

Cauzzi, C., and Faccioli, E., 2018. Anatomy of sigma of a global predictive model for ground motions and response spectra. Bulletin of Earthquake Engineering, 16(5), 1887-1905. DOI: 10.1007/s10518-017-0278-4.

Chen, L. and Faccioli, E., 2013. Single-station standard deviation analysis of 2010-2012 strongmotion data from the Canterbury region, New Zealand. Bulletin of Earthquake Engineering, 11(5), 1617-1632.

Chen Y.H., Tsai C.CP., 2002. A new method for estimation of the attenuation relationship with variance components. Bulletin of the Seismological Society of America, 92, 1984-1991

Cressie, N., and Lahiri, S. N., 1993. The Asymptotic Distribution of REML Estimators. Journal of Multivariate Analysis, 45(2), 217-233. DOI: 10.1006/jmva.1993.1034

Derras, B., Bard, P.-Y., and Cotton, F., 2017. VS30, slope, H800 and f0: performance of various site-condition proxies in reducing ground-motion aleatory variability and predicting nonlinear site response. Earth, Planets and Space, 69. DOI: 10.1186/s40623-017-0718-z

Douglas, J., and Gehl, P., 2008. Investigating strong ground-motion variability using analysis of variance and two-way-fit plots. Bulletin of Earthquake Engineering, 6(3), 389-405. DOI: 10.1007/s10518-008-9063-8

Einarsson P., 1991. Earthquakes and present-day tectonism in Iceland. Tectonophysics, 189, 26179.

Einarsson P., 2008. Plate boundaries, rifts and transforms in Iceland. Jokull, 58, 35-58.

European Committee for Standardization, 2004. Eurocode 8: design of structures for earthquake resistance- Part1: general rules, seismic actions and rules for buildings, European Standard.

Halldorsson, B., and Sigbjörnsson, R., 2009. The Mw6. 3 Ölfus earthquake at 15: 45 UTC on 29 May 2008 in South Iceland: ICEARRAY strong-motion recordings. Soil Dynamics and Earthquake Engineering, 29(6), 1073-1083.

Halldorsson, B., Sigbjörnsson, R., Rupakhety, R., and Chanerley, A. A., 2010. Extreme near-fault strong-motion of the M6.3 Ölfus earthquake of 29 May 2008 in South Iceland. 14th European Conference on Earthquake Engineering (14ECEE) (p. Paper no. 1640). Ohrid, Macedonia.

Hong, H. P., Zhang, Y., and Goda, K., 2009. Effect of spatial correlation on estimated groundmotion prediction equations. Bulletin of the Seismological Society of America, 99(2A), 928934.

Jayaram, N., and Baker, J. W., 2009. Correlation model for spatially distributed ground-motion intensities. Earthquake Engineering \& Structural Dynamics, 38(15), 1687-1708.

Jayaram, N., and Baker, J. W., 2010. Considering spatial correlation in mixed-effects regression and the impact on ground-motion models. Bulletin of the Seismological Society of America, 100(6), 3295-3303.

Joyner, W. B., and Boore, D. M., 1993. Methods for regression analysis of strong-motion data. Bulletin of the Seismological Society of America, 83(2), 469-487.

Ktenidou, O. J., Roumelioti, Z., Abrahamson, N., Cotton, F., Pitilakis, K., and Hollender, F. 2018. Understanding single-station ground motion variability and uncertainty (sigma): Lessons learnt from EUROSEISTEST. Bulletin of Earthquake Engineering, 16(6), 2311-2336.

Kotha, S. R., Bindi, D., and Cotton, F., 2016. Partially non-ergodic region specific GMPE for Europe and Middle-East. Bulletin of Earthquake Engineering, 14(4), 1245-1263. DOI: 10.1007/s10518-016-9875-X 
Kotha, S. R., Bindi, D., and Cotton, F., 2017a. From ergodic to region-and site-specific probabilistic seismic hazard assessment: Method development and application at European and Middle Eastern sites. Earthquake Spectra, 33(4), 1433-1453.

Kotha, S. R., Bindi, D., and Cotton, F., 2017b. Site-Corrected Magnitude- and Region-Dependent Correlations of Horizontal Peak Spectral Amplitudes. Earthquake Spectra, 33(4), 14151432. DOI: $10.1193 / 091416 E Q S 150 M$

Kotha, S. R., Cotton, F., and Bindi, D., 2018. A new approach to site classification: Mixed-effects Ground Motion Prediction Equation with spectral clustering of site amplification functions. Soil Dynamics and Earthquake Engineering, 110, 318-329. DOI: 10.1016/j.soildyn.2018. 01.051

Kowsari, M., Halldorsson, B., Hrafnkelsson, B., Snæbjörnsson, J. P., and Jónsson, S., 2019. Calibration of ground motion models to Icelandic peak ground acceleration data using Bayesian Markov Chain Monte Carlo simulation. Bulletin of Earthquake Engineering, 17(6), 2841-2870

Kowsari, M., Sonnemann, T., Halldorsson, B., Hrafnkelsson, B., Snæbjörnsson, J. P., and Jónsson, S., 2020. Bayesian Inference of Empirical Ground Motion Models to Pseudo-Spectral Accelerations of South Iceland Seismic Zone Earthquakes based on Informative Priors. Soil Dynamics and Earthquake Engineering, 132, 106075. DOI: 10.1016/j.soildyn.2020. 106075

Kramer, S. L., 1996. Geotechnical earthquake engineering. USA: New Jersey: Prentice Hall.

Kuehn, N. M., and Scherbaum, F., 2015. Ground-motion prediction model building: a multilevel approach. Bulletin of Earthquake Engineering, 13(9), 2481-2491. DOI: 10.1007/s10518015-9732-3

Kuehn, N. M., and Scherbaum, F., 2016. A partially non-ergodic ground-motion prediction equation for Europe and the Middle East. Bulletin of Earthquake Engineering, 14(10), 1-14. DOI: 10.1007/s10518-016-9911-x

Lee, Y., Zeng, Y., and Anderson, J. G., 1998. A simple strategy to examine the sources of errors in attenuation relations. Bulletin of the Seismological Society of America, 88(1), 291-296.

Lin, P.S., Chiou, B., Abrahamson, N., Walling, M., Lee, C.T. and Cheng, C.T., 2011. Repeatable source, site, and path effects on the standard deviation for empirical ground-motion prediction models. Bulletin of the Seismological Society of America, 101(5), 2281-2295.

Ming, D., Huang, C., Peters, G. W., and Galasso, C., 2019. An Advanced Estimation Algorithm for Ground-Motion Models with Spatial Correlation. Bulletin of the Seismological Society of America, 109(2), 541-566

Ornthammarath, T., Douglas, J., Sigbjörnsson, R., and Lai, C. G., 2011. Assessment of ground motion variability and its effects on seismic hazard analysis: a case study for iceland. Bulletin of Earthquake Engineering, 9(4), 931-953. DOI: 10.1007/s10518-011-9251-9

Papageorgiou, A. S., and Aki, K., 1983. A specific barrier model for the quantitative description of inhomogeneous faulting and the prediction of strong ground motion. I. Description of the model. Bulletin of the Seismological Society of America, 73(3), 693-722.

Rahpeyma, S., Halldorsson, B., and Green, R. A., 2017. On the Distribution of Earthquake Strongmotion Amplitudes and Site Effects Across the Icelandic Strong-motion Arrays. 16th World Conference on Earthquake Engineering (16WCEE) (p. Paper no. 2762.). Santiago, Chile.

Rahpeyma, S., Halldorsson, B., Hrafnkelsson, B., Green, R. A., and Jónsson, S., 2019. Site effect estimation on two Icelandic strong-motion arrays using a Bayesian hierarchical model for the spatial distribution of earthquake peak ground acceleration. Soil Dynamics and Earthquake Engineering, 120, 369-385. DOI: 10.1016/j.soildyn.2019.02.007

Rahpeyma, S., Halldorsson, B., Hrafnkelsson, B., and Jónsson, S., 2018. Bayesian hierarchical model for variations in earthquake peak ground acceleration within small-aperture arrays. Environmetrics, 29(3), e2497. DOI: 10.1002/env.2497

Rahpeyma, S., Halldorsson, B., Olivera, C., Green, R. A., and Jónsson, S., 2016. Detailed site effect estimation in the presence of strong velocity reversals within a small-aperture strongmotion array in Iceland. Soil Dynamics and Earthquake Engineering, 89, 136-151. DOI: 10.1016/j.soildyn.2016.07.001 
Roberts, G. O., Gelman, A., and Gilks, W. R., 1997. Weak convergence and optimal scaling of random walk Metropolis algorithms. The annals of applied probability, 7(1), 110-120.

Rodriguez-Marek, A., Cotton, F., Abrahamson, N. A., Akkar, S., Al Atik, L., Edwards, B., Montalva, G. A., et al., 2013. A model for single-station standard deviation using data from various tectonic regions. Bulletin of the seismological society of America, 103(6), 31493163.

Rodriguez-Marek, A., Montalva, G. A., Cotton, F., and Bonilla, F., 2011. Analysis of single-station standard deviation using the KiK-net data.Bulletin of the Seismological Society of America, 101(3), 1242-1258.

Sæmundsson, K., and Kristinsson, S., 2005. Hveragerði. Hitamalingar í jarðvegi og sprungur (Hveragerði: Soil temperature measurements and faults) (Geologic mapping No. ÍSOR2005/041) (p. 16). Reykjavík, Iceland: Iceland GeoSurvey (ÍSOR).

Sigbjörnsson, R., Ólafsson, S., Rupakhety, R., Halldorsson, B., Acharya, P., and Snæbjörnsson, J. Th., 2014. Strong-motion Monitoring and Accelerometric Recordings in Iceland. 2nd European Conference on Earthquake and Engineering Seismology (2ECEES) (p. Paper No. 2034). Istanbul, Turkey, 24-29 August 2014.

Sonnemann, T., Halldorsson, B., Hrafnkelsson, B., and Jonsson, S., 2020. Bayesian inference of a physical seismological model for earthquake strong-motion in south Iceland. Soil Dynamics and Earthquake Engineering, 138, 106-219.

Stein, M. L., 2012. Interpolation of spatial data: some theory for Kriging. Springer Science \& Business Media.

Strasser, F. O., Abrahamson, N. A., and Bommer, J. J., 2009. Sigma: Issues, Insights, and Challenges. Seismological Research Letters, 80(1), 40-56. DOI: 10.1785/gssrl.80.1.40

Zhao, J. X., Irikura, K., Zhang, J., Fukushima, Y., Somerville, P. G., Asano, A., Ohno, Y., et al., 2006. An Empirical Site-Classification Method for Strong-Motion Stations in Japan Using h/v Response Spectral Ratio. Bulletin of the Seismological Society of America, 96(3), 914925. DOI: $10.1785 / 0120050124$

Zimmerman, D. L., and Stein, M., 2010. Classical geostatistical methods. Handbook of spatial statistics, 29-44. 


\section{Appendix I}

Table A1. Posterior statistics for hyperparameters $\boldsymbol{\theta}$ along with the total standard deviation for ICEARRAY I. The statistics are given as posterior means and $68^{\text {th }}$ percentiles $( \pm 1 \sigma)$.

\begin{tabular}{|c|c|c|c|c|c|c|c|}
\hline \multirow{2}{*}{$\begin{array}{c}\mathrm{T} \\
{[\mathrm{sec}]}\end{array}$} & \multicolumn{5}{|c|}{$\theta$} & \multirow[b]{2}{*}{$\sigma_{\text {intra }}$} & \\
\hline & $\tau$ & $\phi_{S 2 S}$ & $\phi_{S S}$ & $\phi_{R}$ & $\Delta_{S S}$ & & \\
\hline$P G A$ & $0.1977_{0.1909}^{0.204 *}$ & $0.0915_{0.0675}^{0.1155}$ & $0.1164_{0.1132}^{0.1196}$ & $0.0577_{0.0560}^{0.0593}$ & $0.2536_{0.2284}^{0.2788}$ & 0.1589 & 0.2536 \\
\hline 0.05 & $0.1953_{0.1884}^{0.2022}$ & $0.1048_{0.0783}^{0.1312}$ & $0.1173_{0.1135}^{0.1210}$ & $0.0717_{0.0696}^{0.0738}$ & $0.2608_{0.2331}^{0.2884}$ & 0.1729 & 0.2608 \\
\hline 0.10 & $0.1924_{0.1855}^{0.1993}$ & $0.1680_{0.1269}^{0.2092}$ & $0.1256_{0.1220}^{0.1291}$ & $0.0680_{0.0662}^{0.0698}$ & $0.2926_{0.2507}^{0.3346}$ & 0.2205 & 0.2926 \\
\hline 0.15 & $0.2076_{0.2003}^{0.2149}$ & $0.1982_{0.1552}^{0.2412}$ & $0.1196_{0.1161}^{0.1232}$ & $0.0615_{0.0597}^{0.0634}$ & $0.3170_{0.2732}^{0.3608}$ & 0.2395 & 0.3170 \\
\hline 0.20 & $0.2208_{0.2128}^{0.2289}$ & $0.1897_{0.1416}^{0.2379}$ & $0.1079 \begin{array}{c}0.1120 \\
0.1039\end{array}$ & $0.0719_{0.0703}^{0.0736}$ & $0.3187_{0.2697}^{0.3677}$ & 0.2298 & 0.3187 \\
\hline 0.25 & $0.2296_{0.2215}^{0.2377}$ & $0.1781_{0.1281}^{0.2281}$ & $0.1065_{0.1029}^{0.1102}$ & $0.0644_{0.0628}^{0.0660}$ & $0.3161_{0.2653}^{0.3669}$ & 0.2173 & 0.3161 \\
\hline 0.30 & $0.2312_{0.2237}^{0.2387}$ & $0.1601_{0.1252}^{0.1951}$ & $0.1061_{0.1032}^{0.1090}$ & $0.0569_{0.0555}^{0.0583}$ & $0.3059_{0.2700}^{0.3418}$ & 0.2003 & 0.3059 \\
\hline 0.40 & $0.2421_{0.2343}^{0.2500}$ & $0.1299_{0.0951}^{0.1646}$ & $0.0949_{0.0920}^{0.0978}$ & $0.0633_{0.0620}^{0.0649}$ & $0.2975_{0.2617}^{0.3333}$ & 0.1729 & 0.2975 \\
\hline 0.50 & $0.2417_{0.2339}^{0.2495}$ & $0.1011_{0.0730}^{0.1292}$ & $0.0840_{0.0801}^{0.0879}$ & $0.0721_{0.0708}^{0.0734}$ & $0.2844_{0.2550}^{0.3139}$ & 0.1499 & 0.2844 \\
\hline 1.00 & $0.1896_{0.1836}^{0.1956}$ & $0.0829_{0.0541}^{0.1117}$ & $0.0550_{0.0508}^{0.0592}$ & $0.0708_{0.0697}^{0.0719}$ & $0.2255_{0.1957}^{0.2553}$ & 0.1221 & 0.2255 \\
\hline
\end{tabular}

*Posterior mean values with $16^{\text {th }}$ percentile (subscript) and $84^{\text {th }}$ percentile (superscript) given for each period. 


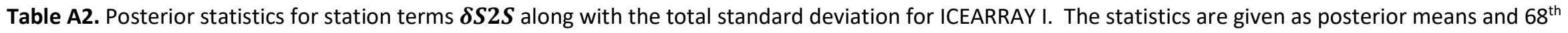
percentiles $( \pm 1 \sigma)$.

\begin{tabular}{|c|c|c|c|c|c|c|c|c|c|c|}
\hline \multirow{3}{*}{$\begin{array}{c}\mathrm{T} \\
{[\mathrm{sec}]}\end{array}$} & \multicolumn{10}{|c|}{$\delta S 2 S$} \\
\hline & IS601 & IS602 & IS603 & IS604 & IS605 & IS607 & IS608 & IS609 & IS611 & IS612 \\
\hline & $\delta S 2 S_{1}$ & $\delta S 2 S_{2}$ & $\delta S 2 S_{3}$ & $\delta S 2 S_{4}$ & $\delta \mathrm{S}_{2} \mathrm{~S}_{5}$ & $\delta S 2 S_{6}$ & $\delta S 2 S_{7}$ & $\delta S 2 S_{8}$ & $\delta S 2 S_{9}$ & $\delta S 2 S_{10}$ \\
\hline$P G A$ & $0.13933_{0.1069}^{0.1716 *}$ & $-0.0443_{-0.0767}^{-0.0120}$ & $-0.0610_{-0.0932}^{-0.0289}$ & $-0.0828_{-0.1150}^{-0.0506}$ & $0.0580_{0.0259}^{0.0902}$ & $0.0518_{0.0196}^{0.0841}$ & $0.0373_{0.0049}^{0.0697}$ & $0.0149 \begin{array}{r}0.0473 \\
-0.0175\end{array}$ & $-0.0841_{-0.1164}^{-0.0518}$ & $-0.0409_{-0.0734}^{-0.0083}$ \\
\hline 0.05 & $0.1008_{0.0639}^{0.1377}$ & $-0.02433_{-0.0610}^{0.0124}$ & $-0.1225_{-0.1591}^{-0.0858}$ & $-0.1058_{-0.1424}^{-0.0692}$ & $0.0690_{0.0324}^{0.1056}$ & $-0.0105_{-0.0472}^{0.0262}$ & $0.0461_{0.0094}^{0.0829}$ & $-0.0635_{-0.1003}^{-0.0267}$ & $-0.0053 \begin{array}{r}0.0313 \\
-0.0419\end{array}$ & $0.0832_{0.0463}^{0.1201}$ \\
\hline 0.10 & $0.1922 \begin{array}{l}0.2520 \\
0.1324\end{array}$ & $-0.0890_{-0.1486}^{-0.0294}$ & $-0.0194 \begin{array}{r}0.0403 \\
-0.0791 \\
\end{array}$ & $-0.0519 \begin{array}{r}0.0078 \\
-0.1116\end{array}$ & $0.1951_{0.1354}^{0.2548}$ & $0.1768 \begin{array}{l}0.2366 \\
0.1170\end{array}$ & $-0.0143 \quad \begin{array}{r}0.0454 \\
-0.0740\end{array}$ & $0.0027 \begin{array}{r}0.0624 \\
-0.0570 \\
\end{array}$ & $-0.2053 \begin{array}{l}-0.1457 \\
-0.2649\end{array}$ & $-0.1018_{-0.1618}^{-0.0419}$ \\
\hline 0.15 & $0.2579 \begin{array}{c}0.3262 \\
0.1895\end{array}$ & $0.0343 \begin{array}{r}0.1027 \\
-0.0341\end{array}$ & $0.0055_{-0.0628}^{0.0738}$ & $0.0522 \begin{array}{r}0.1205 \\
-0.0161 \\
\end{array}$ & $0.1515_{0.0831}^{0.2198}$ & $0.2702 \begin{array}{l}0.3385 \\
0.2018\end{array}$ & $-0.0313{ }_{-0.0997}^{0.0370}$ & $-0.1932_{-0.2616}^{-0.1248}$ & $-0.2167_{-0.2851}^{-0.1483}$ & $-0.2223_{-0.2907}^{-0.1538}$ \\
\hline 0.20 & $0.2117 \begin{array}{l}0.2770 \\
0.1465\end{array}$ & $0.0002 \begin{array}{r}0.0654 \\
-0.0649\end{array}$ & $0.0313 \begin{array}{r}0.0964 \\
-0.0338 \\
\end{array}$ & $0.1091_{0.0441}^{0.1742}$ & $0.1349 \begin{array}{c}0.2000 \\
0.0699\end{array}$ & $0.1792_{0.1141}^{0.2444}$ & $0.0868_{0.0218}^{0.1519}$ & \begin{tabular}{|c|}
$-0.1968_{-0.2618}^{-0.1318}$ \\
\end{tabular} & $-0.2311_{-0.2961}^{-0.1661}$ & $-0.2172_{-0.2824}^{-0.1521}$ \\
\hline 0.25 & $0.1954 \begin{array}{l}0.2573 \\
0.1335\end{array}$ & $-0.0046 \underset{-0.0663}{0.0571}$ & $0.0291 \begin{array}{r}0.0908 \\
-0.0326\end{array}$ & $0.1294 \begin{array}{l}0.1911 \\
0.0677\end{array}$ & $0.1640_{0.1022}^{0.2257}$ & $0.1583 \begin{array}{c}0.2199 \\
0.0966\end{array}$ & $0.0526{ }_{-0.0091}^{0.1143}$ & $-0.1732_{-0.2350}^{-0.1114}$ & $-0.2283_{-0.2900}^{-0.1666}$ & $-0.1799_{-0.2417}^{-0.1181}$ \\
\hline 0.30 & $0.1950_{0.1402}^{0.2498}$ & $-0.0082{ }_{-0.0629}^{0.0465}$ & $0.0030_{-0.0517}^{0.0576}$ & $0.1157_{0.0611}^{0.1703}$ & $0.1773_{0.1227}^{0.2320}$ & $0.1494_{0.0949}^{0.2040}$ & $0.0194_{-0.0354}^{0.0741}$ & $-0.1656_{-0.2202}^{-0.1109}$ & $-0.2104_{-0.2650}^{-0.1558}$ & $-0.1494_{-0.2042}^{-0.0947}$ \\
\hline 0.40 & $0.1531_{0.1078}^{0.1984}$ & $0.0144{ }_{-0.0309}^{0.0597}$ & $-0.0203 \begin{array}{r}0.0248 \\
-0.0655 \\
\end{array}$ & $0.1097 \begin{array}{l}0.1549 \\
0.0646\end{array}$ & $0.1043_{0.0592}^{0.1494}$ & $0.1396_{0.0945}^{0.1847}$ & $\begin{array}{rr}0.0187 & 0.0265 \\
-0.0639 \\
\end{array}$ & $-0.1351_{-0.1803}^{-0.0899}$ & $-0.1579_{-0.2030}^{-0.1129}$ & $-0.0950_{-0.1403}^{-0.0498}$ \\
\hline 0.50 & $0.1189 \begin{array}{c}0.1544 \\
0.0835\end{array}$ & $0.0153 \begin{array}{r}0.0508 \\
-0.0201 \\
\end{array}$ & $-0.0257 \begin{array}{r}0.0096 \\
-0.0610\end{array}$ & $0.0963 \begin{array}{c}0.1317 \\
0.0609\end{array}$ & $0.0420_{0.0066}^{0.0774}$ & $0.1139 \begin{array}{c}0.1494 \\
0.0783\end{array}$ & $-0.0361_{-0.0715}^{-0.0007}$ & $-0.1068_{-0.1422}^{-0.0713}$ & $-0.1148_{-0.1502}^{-0.0795}$ & $-0.0556_{-0.0911}^{-0.0201}$ \\
\hline 1.00 & $0.0759 \begin{array}{c}0.1052 \\
0.0466\end{array}$ & $-0.0027 \begin{array}{r}0.0267 \\
-0.0321\end{array}$ & $0.0058_{-0.0235}^{0.0351}$ & $0.1092 \begin{array}{r}0.1386 \\
-0.0798\end{array}$ & $-0.0184 \underset{-0.0477}{0.0109}$ & $0.0316_{0.0022}^{0.0611}$ & $-0.0880_{-0.1174}^{-0.0586}$ & $-0.0551_{-0.0845}^{-0.0257}$ & $-0.0290 \begin{array}{r}0.0003 \\
-0.0584\end{array}$ & $0.0069 \underset{-0.0225}{0.0362}$ \\
\hline
\end{tabular}

*Posterior mean values with $16^{\text {th }}$ percentile (subscript) and $84^{\text {th }}$ percentile (superscript) given for each period. 
Table A3. Posterior statistics for the latent parameters $\boldsymbol{\beta}$, i.e., the coefficients of the GMM for ICEARRAY I. The statistics are given as posterior means and $68^{\text {th }}$ percentiles $( \pm 1 \sigma)$.

\begin{tabular}{|c|c|c|c|c|}
\hline \multirow{2}{*}{$\mathrm{T}[\mathrm{sec}]$} & \multicolumn{4}{|c|}{$\beta$} \\
\cline { 2 - 5 } & $\beta_{1}$ & $\beta_{2}$ & $\beta_{3}$ & $\beta_{4}$ \\
\hline$P G A$ & $0.8807_{0.8329}^{0.9286 *}$ & $0.7056_{0.6906}^{0.7206}$ & $-2.8645_{-2.9414}^{-2.7875}$ & $0.0923_{0.0853}^{0.0994}$ \\
\hline 0.05 & $1.2824_{1.2306}^{1.3342}$ & $0.6415_{0.6262}^{0.6568}$ & $-2.7529_{-2.8328}^{-2.6730}$ & $0.0923_{0.0852}^{0.0994}$ \\
\hline 0.10 & $1.0093_{0.9398}^{1.0788}$ & $0.7952_{0.7803}^{0.8101}$ & $-2.7969_{-2.8765}^{-2.7173}$ & $0.0802_{0.0731}^{0.0872}$ \\
\hline 0.15 & $0.7181_{0.6400}^{0.7961}$ & $0.8857_{0.8702}^{0.9013}$ & $-2.8871_{-2.9674}^{-2.8069}$ & $0.0746_{0.0673}^{0.0820}$ \\
\hline 0.20 & $0.3731_{0.2967}^{0.4494}$ & $0.8968_{0.8802}^{0.9134}$ & $-2.6581_{-2.7132}^{-2.5730}$ & $0.0541_{0.0464}^{0.0619}$ \\
\hline 0.25 & $0.0798_{0.0059}^{0.1536}$ & $0.8764_{0.8595}^{0.8934}$ & $-2.4063_{-2.4916}^{-2.3210}$ & $0.0408_{0.0329}^{0.0487}$ \\
\hline 0.30 & $-0.0129_{-0.0795}^{0.0538}$ & $0.8892_{0.8731}^{0.9054}$ & $-2.5674_{-2.6458}^{-2.4891}$ & $0.0533_{0.0455}^{0.0611}$ \\
\hline 0.40 & $-0.2825_{-0.3430}^{-0.2220}$ & $0.7773_{0.7607}^{0.7940}$ & $-2.1366_{-2.2151}^{-2.0581}$ & $0.0363_{0.0285}^{0.0441}$ \\
\hline 0.50 & $-0.4481_{-0.5014}^{-0.3948}$ & $0.6593_{0.6428}^{0.6659}$ & $-1.7445_{-1.8227}^{-1.6662}$ & $0.0233_{0.0154}^{0.0312}$ \\
\hline 1.00 & $-0.7146_{-0.7570}^{-0.6723}$ & $0.3278_{0.3149}^{0.3406}$ & $-0.8753_{-0.9355}^{-0.8151}$ & $0.0073_{0.0011}^{0.0135}$ \\
\hline
\end{tabular}

*Posterior mean values with $16^{\text {th }}$ percentile (subscript) and $84^{\text {th }}$ percentile (superscript) given for each period.

Table A4. Relative ratio between ICEARRAY I stations located on lava-rock and the average of station terms located on rock (i.e., IS609, IS611, and IS612).

\begin{tabular}{|c|c|c|c|c|c|c|c|}
\hline \multirow{3}{*}{$\begin{array}{c}\mathrm{T} \\
{[\mathrm{sec}]}\end{array}$} & \multicolumn{7}{|c|}{$\delta S 2 S_{s} / \delta S 2 S_{r}^{*}$} \\
\hline & 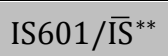 & 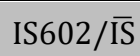 & IS603/Ī & 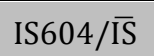 & 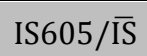 & 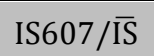 & 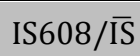 \\
\hline & $\delta S 2 S_{1}$ & $\delta S 2 S_{2}$ & $\delta S 2 S_{3}$ & $\delta S 2 S_{4}$ & $\delta \mathrm{S}^{2} \mathrm{~S}_{5}$ & $\delta S 2 S_{6}$ & $\delta S 2 S_{7}$ \\
\hline$P G A$ & 1.49 & 0.98 & 0.94 & 0.90 & 1.24 & 1.22 & 1.18 \\
\hline 0.05 & 1.24 & 0.93 & 0.74 & 0.77 & 1.15 & 0.96 & 1.09 \\
\hline 0.10 & 1.93 & 1.01 & 1.19 & 1.10 & 1.94 & 1.86 & 1.20 \\
\hline 0.15 & 2.94 & 1.76 & 1.64 & 1.83 & 2.30 & 3.02 & 1.51 \\
\hline 0.20 & 2.67 & 1.64 & 1.76 & 2.11 & 2.34 & 2.48 & 2.00 \\
\hline 0.25 & 2.45 & 1.54 & 1.67 & 2.10 & 2.28 & 2.25 & 1.76 \\
\hline 0.30 & 2.34 & 1.47 & 1.50 & 1.95 & 2.25 & 2.11 & 1.56 \\
\hline 0.40 & 1.91 & 1.39 & 1.28 & 1.73 & 1.71 & 1.85 & 1.29 \\
\hline 0.50 & 1.62 & 1.28 & 1.16 & 1.54 & 1.36 & 1.60 & 1.14 \\
\hline 1.00 & 1.26 & 1.05 & 1.07 & 1.36 & 1.02 & 1.14 & 0.86 \\
\hline
\end{tabular}

